\title{
Trivium
}

Revue franco-allemande de sciences humaines et sociales - Deutsch-französische Zeitschrift für Geistesund Sozialwissenschaften

$4 \mid 2009$

Les « religions orientales » dans le monde grec et romain

\section{Wurden die Eingeweihten der Mithras-Mysterien auf der Stirn gekennzeichnet? Für eine neue Lesart von Tertullians De Praescr. 40, 4}

\section{Luc Renaut}

Traducteur : Nicola Denis

\section{OpenEdition Journals}

Édition électronique

URL : http://journals.openedition.org/trivium/3465

DOI : $10.4000 /$ trivium.3465

ISSN : $1963-1820$

Éditeur

Les éditions de la Maison des sciences de l'Homme

\section{Référence électronique}

Luc Renaut, « Wurden die Eingeweihten der Mithras-Mysterien auf der Stirn gekennzeichnet? Für eine neue Lesart von Tertullians De Praescr. 40, 4 », Trivium [Online], 4 | 2009, online erschienen am 23 Oktober 2009, abgerufen am 08 September 2020. URL : http://journals.openedition.org/trivium/3465 : DOI : https://doi.org/10.4000/trivium.3465

Ce document a été généré automatiquement le 8 septembre 2020.

\section{c) (ㅇ)}

Les contenus des la revue Trivium sont mis à disposition selon les termes de la Licence Creative Commons Attribution - Pas d'Utilisation Commerciale - Pas de Modification 4.0 International. 


\title{
Wurden die Eingeweihten der Mithras-Mysterien auf der Stirn gekennzeichnet? Für eine neue Lesart von Tertullians De Praescr. 40, 4
}

\author{
Luc Renaut
}

Traduction : Nicola Denis

\section{NOTE DE L'ÉDITEUR}

Wir danken Luc Renaut und dem Verlag Fabrizio Serra für die freundliche Genehmigung, diesen Artikel zu übersetzen. Bei den Abbildungen handelt es sich um Zeichnungen des Autors.

\section{Einleitung}

1 Von Celsus über Justin den Märtyrer, Tertullian und Renan bis zu Cumont sind die Mithras-Mysterien immer wieder mit dem Christentum in Zusammenhang gebracht worden. Insbesondere Tertullian wollte unbedingt in mehreren angeblich mithraischen Bestandteilen des Rituals diabolische Nachahmungen auf Kosten der christlichen Sakramente erkennen. Um das Jahr 200 hält er in De praescr. 40, 4, dem Teufel vor, »die Mithras-Soldaten auf der Stirn zu kennzeichnen" (signare in frontibus milites suos [i.e. Mithrae]) ${ }^{1}$, eine berühmte Formulierung, die zu zahlreichen Mutmaßungen Anlass gegeben hat: Handelt es sich um eine Neuauflage der soldatischen Kennzeichnung, wie man sie aus der Kaiserzeit kennt (Cumont)? Um einen Ritus analog zur christlichen 
signatio (Bekreuzigung) (Dölger, Perdrizet)? Um eine schmerzhafte Kauterisierung ihrer Glaubensbrüder, mit der die leones betraut waren (Turcan)?

2 Der signatio Mithrae könnte es mithin gelungen sein, über die verwirrende Nähe zum christlichen Sakrament der Firmung hinaus, der römischen Welt die absichtliche Brandmarkung der Haut gleichsam als Heil versprechendes Viatikum zu verordnen. Doch offen gestanden wird die vermeintliche rituelle Verwandtschaft selten ohne Hintergedanken betrachtet. Indirekt wird so nämlich der christlichen signatio ein Ehrentitel zugesprochen, der der mithraischen Kennzeichnung angeblich fehlte: Hat das Christentum nicht ein unsichtbares Zeichen der Zugehörigkeit, ein geistiges Siegel, erfunden, während sich die Mithras-Anhänger damit begnügten, das Fleisch zu schänden? Gewiss handle es sich um zwei allogene Riten, einmal judäischen, einmal persischen Ursprungs, doch während dieser barbarisch geblieben sei, hätte sich jener zu zivilisieren verstanden.

3 Gesetzt den Fall, man ist bereit, zu den Quellen zurückzukehren, hat diese vereinfachende Vorstellung keine Existenzberechtigung mehr.

\section{Tätowierung, Kauterisierung, Salbung?}

4 Wir wissen wenig über die Stellung des Miles im Mithraismus. Im Mithräum des Felicissimus in Ostia (Mitte des 3. Jahrhunderts) verweisen die drei Attribute des Miles auf das Soldatentum: geknoteter Beutel, Helm und Lanze. Man stimmt gleichfalls darin überein, in der modellierten geharnischten Figur auf der Kultvase aus Mainz/ Mogontiacum einen Miles zu erkennen. ${ }^{2}$

5 In seinem De corona (aus dem Jahr 211) widmet Tertullian der Initiation der MithrasSoldaten einige Zeilen. Eines der Hauptanliegen dieses Textes besteht darin, die Nichtigkeit soldatischer Ehren und, damit verbunden, der soldatischen Laufbahn als solcher unter Beweis zu stellen. Schenkt man Tertullian Glauben, dann hat die Initiation der milites Mithrae ein Ritual umfasst, in dem sich eine Verachtung irdischen Ruhms aussprach, die der im Christentum gepredigten vergleichbar war:

[Miles] cum initiatur in spelaeo, in castris vere tenebrarum, coronam interposito gladio sibi oblatam, quasi mimum martyrii, dehinc capiti suo accommodatam, monetur obuia manu a capite pellere et in hume rum, si forte, transferre dicens Mithran esse coronam suam. Atque exin de numquam coronatur, idque in signum habet ad probationem sui, sicubi temptatus fuerit de sacramento, statimque credi tur Mithrae miles, si deiecerit coronam, si eam in deo suo esse dixerit. Agnoscamus ingenia diaboli, idcirco quaedam de diuinis affectantis ut nos de suorum fide confundat et iudicet. ${ }^{3}$

»Wenn der Soldat in einer Grotte, einer wahren >Burg` der Finsternis, eingeweiht wird, wird ihm über ein dazwischen gehaltenes Schwert [oder: unter der Bedrohung mit einem Schwert] $]^{4}$ ein Kranz dargereicht - fast wie eine Nachäffung des Martyriums - und dieser ihm dann auf den Kopf gelegt; er wird aufgefordert, ihn mit der Hand wegzuschieben und mit den Worten, Mithras ist mein Kranz, etwa auf die Schulter fallen zu lassen. Von diesem Augenblick an bekränzt er sich nie mehr, und darin besteht das Zeichen, das er für seine Hingabe setzt, sollte man ihn je im Hinblick auf seinen Eid auf die Probe stellen: Er gilt als Mithras-Soldat, sobald er den Kranz zu Boden geworfen und gesagt hat, sein Gott nehme die Stelle des Kranzes ein. Lasst uns hier die Einfälle des Teufels erkennen: Er zieht absichtlich bestimmte Dinge der Religion in den Schmutz, um uns zu demütigen und uns an der Elle der seinen zu messen.« 
6 Folgt man diesem Text, dann wird der Miles-Anwärter, zusammenfassend gesagt, mit einem Schwert und einem Kranz konfrontiert und stellt genau im Zurückweisen dieses Kranzes seine Bindung an Mithras unter Beweis. Dieser Abschnitt wurde gelegentlich mit Predella-Darstellungen in Zusammenhang gebracht, in denen der Strahlenkranz der Sonne (Sol) auf dem Boden zwischen einer knienden Figur (Sol?) und einer anderen, aufrecht stehenden (Mithras?) liegt. ${ }^{5}$ Andere Darstellungen, insbesondere in Capua, zeigen von einem außenstehenden Dritten (Fackel- oder Schwertträger?) bedrohte Eingeweihte.

7 Die mit dem Rang des Miles verbundenen Symbole und Attribute verweisen auf das Militärische. Trifft das auch auf die in De Praescr. 40, 4, erwähnte signatio zu? Vielfach sah man in der Formel signare in frontibus milites suos einen Ritus, der sich an die körperliche Kennzeichnung der römischen Soldaten anlehnte. Der Text von Vegetius verweist darauf, dass man dabei Tätowierungen nutzte. ${ }^{6}$ Es gibt hingegen keinen Anhaltspunkt, um diese Praktik für die Epoche Tertullians nachweisen zu können. Häufig werden die Acta Maximiliani ${ }^{7}$ zitiert, in denen die Leiden eines jungen christlichen Rekruten aufgeführt werden, der während der Herrschaft Diokletians gelebt haben soll. Wie jedoch mehrere Kommentatoren bemerkt haben, wurden diese Acta möglicherweise erst Ende des 4. oder Anfang des 5. Jahrhunderts verfasst (beziehungsweise überarbeitet). ${ }^{8}$ Darüber hinaus ist dort nicht von Tätowierungen die Rede, sondern von einer am Hals der neuen Rekruten befestigten Erkennungsmarke (Tessera). Wenn ein solcher Gegenstand im römischen Heer benutzt worden wäre, hätte die Archäologie zweifelsohne wenigstens vereinzelte Exemplare zutage gefördert. Wie David Woods kürzlich gezeigt hat, ähnelt das plumbum Maximilians den Bleisiegeln, die die Omaijaden am Hals der für die Steuer (jizya) aufkommenden Nicht-Muslime befestigten. Diese Praktik wird durch Quellentexte und archäologische Forschungen ausdrücklich bezeugt; zusammen mit den übrigen Sachverhalten veranlasst sie David Woods sogar dazu, das Entstehungsdatum der Acta Maximiliani beträchtlich vorzuverlegen. Ihm zufolge sind sie einem Christen aus Karthago im 8. Jahrhundert zuzuschreiben und haben als Aufruf zum Widerstand gegen die arabische Vorherrschaft zu gelten. ${ }^{9}$ Damit hätten wir uns entsprechend weit von den bei der Rekrutierung von Soldaten üblichen tetrarchischen Praktiken entfernt.

Das von Vegetius beschriebene Kennzeichnen der Soldaten wird wiederholt bei den Kirchenvätern ${ }^{10}$ erwähnt, doch von keinem vor 390 . Cyrillus von Jerusalem könnte, um 350, eine Ausnahme darstellen: In seinen Taufkatechesen scheinen in der Tat mehrere Passagen auf die militärische Kennzeichnung anzuspielen. ${ }^{11}$ Doch diese Frage kann hier nicht erörtert werden. Beschränken wir uns darauf, dass den Text Tertullians mindestens 150 Jahre von den ersten Erwähnungen der militärischen Praktik trennen. De praescr. kann also gar nicht darauf anspielen, im Gegensatz zu der von Franz Cumont vertretenen Ansicht:

»[D]as Zeichen oder Siegel, das man [bei den Mithras-Mysterien] ihm [dem Soldaten] gab, [scheint] nicht eine Salbung, wie in der christlichen Liturgie, sondern ein mit einem glühenden Eisen aufgebranntes Mal gewesen zu sein, ähnlich demjenigen, welches man in der Armee den Rekruten vor ihrer Zulassung zum Eide aufzudrücken pflegte. «12

Schon zu Beginn des 20. Jahrhunderts hat sich die Hypothese einer Kauterisierung zahlreichen Gelehrten als plausibel aufgedrängt. ${ }^{13}$ Bereits 1911 jedoch meinte Franz Josef Dölger, da Tertullian die Mithras-Mysterien mit der christlichen Initiation vergleiche, könne signare analog zu der im Christentum praktizierten ölung auch nur 
eine Signierung mit Öl bezeichnen. ${ }^{14}$ Dieser Meinung ist auch Paul Perdrizet: Tertullian spreche von einem "symbolischen, der christlichen Firmung vergleichbaren Ritus « ${ }^{15}$ Diese Position sollte sich allerdings nicht durchsetzen. Die Schuld daran trägt aller Wahrscheinlichkeit nach Dölger, der schließlich 1929 die signatio in frontibus als Tätowierung auf der Stirn auffasst. ${ }^{16}$ Cumont greift diese Vorstellung zu Anfang der 30er Jahre wieder auf, indem er die Lücken auf einem aus Oxyrhynchos stammenden Papyrus mit mysterienhaltigem Anstrich, das damals gerade in den Papiri greci e latini veröffentlicht worden war, fantasievoll füllt. ${ }^{17}$ In den Zeilen $15-17$ veranlasst das Wort ỏ Ł́couv Cumont zu dem Glauben, er habe es mit einer Art Nadeltätowierung zu tun:

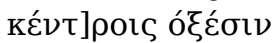

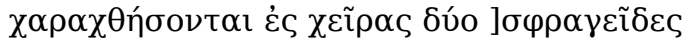

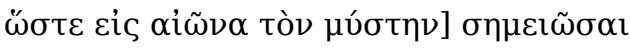
»[Mit Hilfe von] gestählten [Nadeln] [Ritzt man in seine Hände zwei] Siegel, [Um den Mysten auf ewig zu] zeichnen.«

Diese gewagte Rekonstruktion sollte häufig unhinterfragt zitiert werden. ${ }^{18}$ Sie findet sich etwa in dem äußerst spekulativen Beitrag, den Wilhelm Vollgraff einer im Mithräum von S. Prisca in Rom aufgefundenen Terrakotta (um 200) widmet. ${ }^{19}$ Das unleserliche, auf den Gefäßrand gekritzelte Graffito zeige die Wörter te cauterio (»ich kauterisiere dich«): »Darin besteht ohne Frage die Einweihungsformel, die der Priester gebrauchte, um, wie Tertullian sagt, die Mithras-Soldaten rauf der Stirn $\mathrm{zu}$ kennzeichnen « ${ }^{20}$ Ebenso könnte, so mutmaßt Vollgraff, der nur undeutlich zu erkennende längliche Gegenstand, den der Mystagoge (ein Pater?) auf den (stark in Mitleidenschaft) gezogenen Fresken der Bänke des Mithräums in Capua in der Hand hält, »ein mit einem langen Griff versehenes heißes Eisen« sein. In seiner Studie zum Mithräum von S. Prisca übernimmt Maarten Vermaseren Vollgraffs Schlussfolgerungen und geht davon aus, Saal Z, ein Nebenraum des Hauptheiligtums, in dem die Terrakotta gefunden worden war, sei für die Prüfungen des »Scheintodes« und des cauterium vorgesehen gewesen. ${ }^{21}$

Ein weiterer denkwürdiger Versuch stammt von Helga von Heintze, die sich nicht scheute, aus dem über das Gemenge gebietenden General auf dem Ludovisi-Sarkophag (Abb. 1) einen Eingeweihten der Mithras-Mysterien zu machen. ${ }^{22}$ Weist er auf der Stirn nicht ein kreuzförmiges Zeichen auf? Andere Porträtdarstellungen zeigen allerdings ähnliche Zeichen (Abb.2), über deren Bedeutung kein Zweifel besteht: Wie Dölger bereits vorgeschlagen hatte ${ }^{23}$, zeigen sie höchstwahrscheinlich Narben, die von frontal zugefügten Verletzungen stammen und als Zeichen für Tapferkeit in der Schlacht galten. ${ }^{24}$ Diese Erklärung trifft meiner Ansicht nach gleichfalls auf die vollplastisch gearbeiteten »Kahlköpfe« aus dem 1. Jahrhundert vor Christi zu, die gelegentlich eine einfache oder kreuzförmige Narbe oberhalb der Stirn aufweisen. ${ }^{25}$ Die Chirurgen der Antike rieten im Übrigen dazu, Schädelbrüche einzurichten, indem der Knochen durch einen kreuzförmigen Einschnitt bloßgelegt wurde. ${ }^{26}$ 


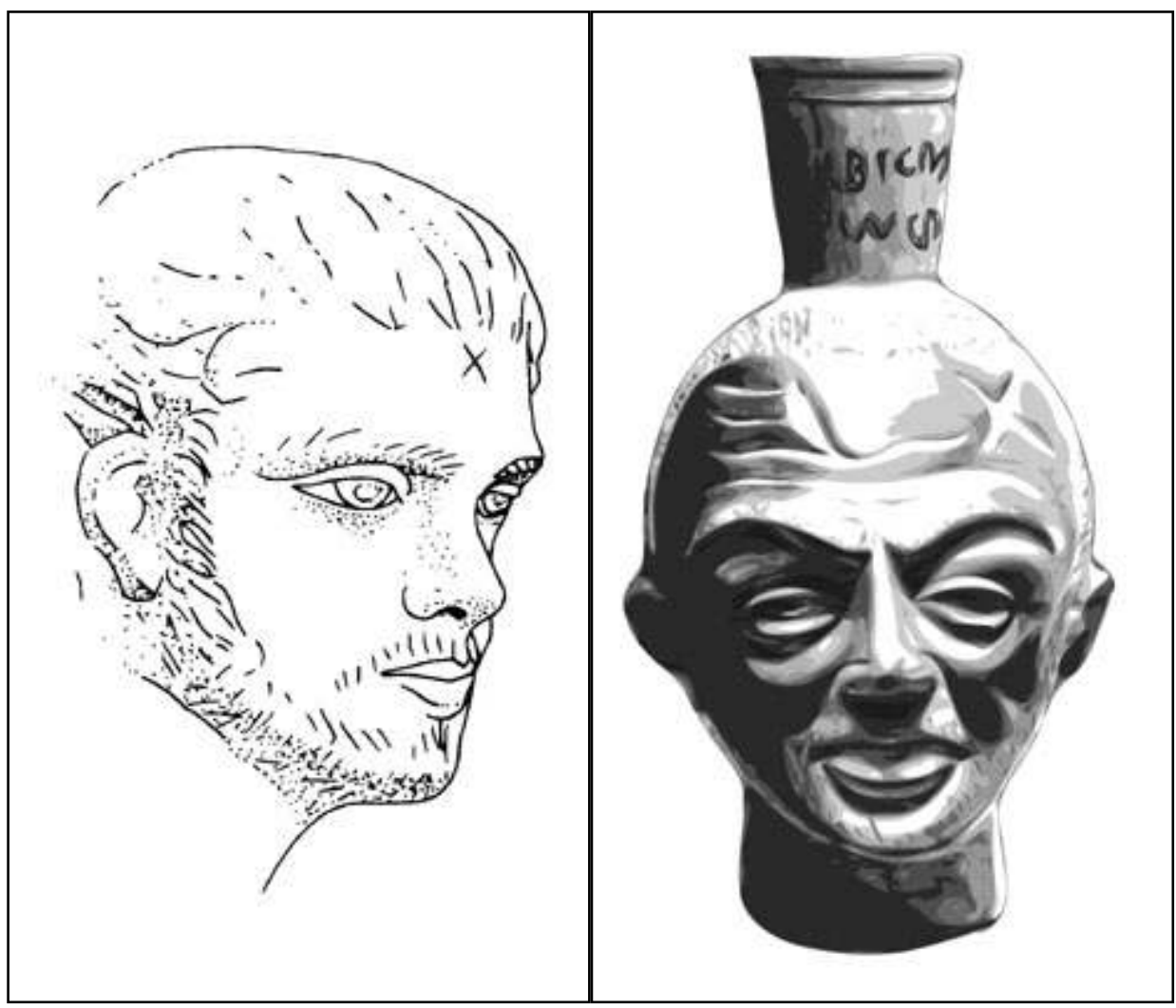

Abb. 1 Ludovisi-Sarkophag (3. Jh.)

Abb. 2 El-Aouja (Tunesien): Kopfgefäß (3. Jh.)

Per Beskow hat der signatio mithriaca mehrere Seiten gewidmet. ${ }^{27}$ In Bezug auf das Phänomen, das er unumwunden als »scholary myth« bezeichnet, bleibt er skeptisch. Es gelingt ihm indes nicht, die Passage aus De praescr. zu entkräften, sodass er sich gezwungen sieht, die Existenz eines wirklichen Bekreuzigungs-Rituals anzuerkennen: "Tertullianus says that some kind of sign or mark was given on the forehead of the initiates of Mithras, more precisely at the Miles grade. The nature of this sign is unknown." Meines Wissens nach hat Manfred Clauss zu dieser Frage nie Stellung bezogen..$^{28}$ Die Diskussion erfuhr in den 1990er Jahren einen neuen Anstoß durch Robert Turcan, der sich zu einem glühenden Verteidiger für die Existenz einer Kauterisierung in den Mithras-Mysterien aufschwang. ${ }^{29}$

Die folgenden Ausführungen werden hoffentlich zeigen, wie brüchig der Boden ist, auf dem die Anhänger einer rituellen Kennzeichnung im Mithraismus ihre Argumente vortragen.

\section{Die Feuerprüfung und die leones des Mithras}

In seiner Polemik gegen Julian Apostata führt Gregor von Nazianz die diversen körperlichen Kasteiungen auf, die Mythologie und Götzenkulte ihren Helden oder Gläubigen abverlangen. Er erwähnt darunter auch »die wohlverdienten rituellen

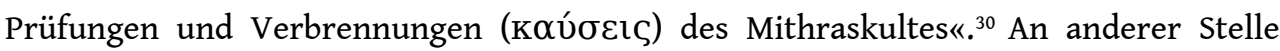
freut er sich über das Verschwinden der heidnischen Ungehörigkeiten: „Schluss mit 
den wohlverdienten mithraischen Züchtigungen [die denen zugefügt werden], die es aushalten, in solche Mysterien eingeweiht zu werden «.$^{31}$ stoßen. Im 6. Jahrhundert behauptet Nonnos Mythographus, Mithras habe seinen

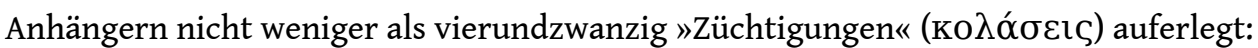

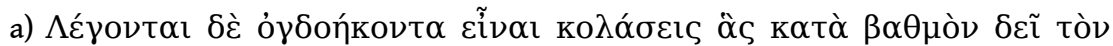

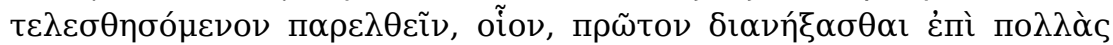

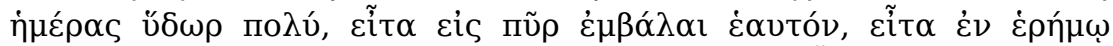

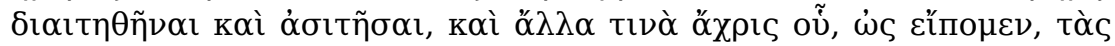

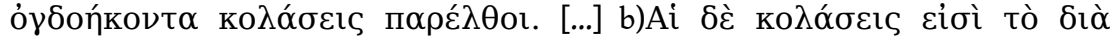

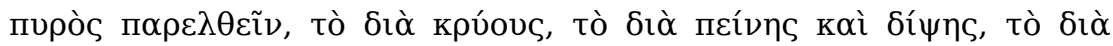

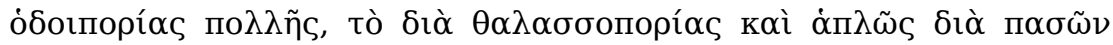

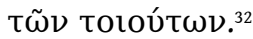

a) »Die Züchtigungen sollen sich auf die Anzahl von achtzig belaufen; der Initiand muss sie der Reihe nach ablegen: also zuerst lange durch ein großes Gewässer schwimmen, sich in Feuer stürzen, in der Wüste leben und fasten, und all diese Dinge, bis er, wie gesagt, die achtzig Prüfungen abgelegt hat. [...] b) $\mathrm{Zu}$ den Züchtigungen zählen das Aushalten von Feuer, Kälte, Hunger und Durst, ein langer Gang, eine Fahrt auf dem Meer, kurzum, all diese Dinge."

Die letzten von diesem Verfasser ${ }^{33}$ zusammengestellten Prüfungen sehen wie folgt aus:

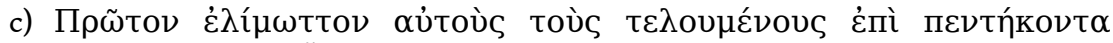

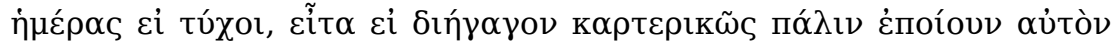

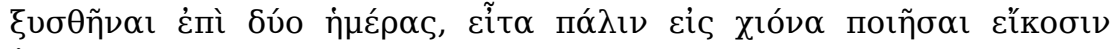
$\dot{\eta} \mu \varepsilon_{\rho} \rho{ }^{\circ}{ }^{34}$

c) »Man ließ die Eingeweihten zunächst fünfzig Tage lang fasten, wenn sie dazu in der Lage waren; wenn er sich dann als ausdauernd erwies, ließ man ihn zwei Tage lang mit einem Badeschaber abreiben, daraufhin hieß man ihn zwanzig Tage im Schnee verbringen."

Woher stammt dieses unglaubliche Verzeichnis? Es handelt sich schlichtweg um nichts anderes als eine Karikatur der Aktivitäten der Palästra, der Bäder und der Ausbildung der Epheben. Nonnos Mythographus, der über den persischen Ursprung des Mithras im Bilde ist, hat sich möglicherweise an der äußerst umfassenden Ausbildung orientiert, der nach Strabos Ausführungen die jungen Perser unterzogen wurden:

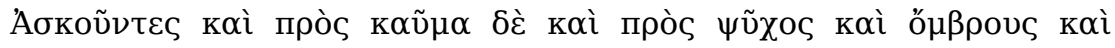

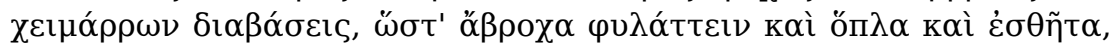

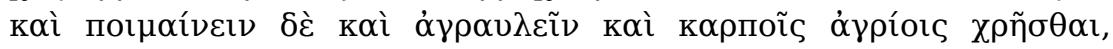

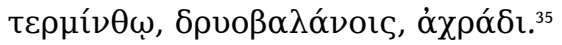

»Sie setzen sich dem Brennen [der Sonne], der Kälte und dem Regen aus; sie üben sich darin, reißende Strömungen zu durchqueren, ohne ihre Waffen und ihr Gepäck zu benetzen; sie versuchen sich auch im Hirtenleben, schlafen auf dem Feld, ernähren sich von wild wachsenden Früchten: Pistazien, Eicheln oder Birnen.«

Man sieht, wie leicht es ist, die von Nonnos Mythographus zusammengestellten Ausmalungen zu entkräften. Sollte man darum aber den wenigen Worten des Gregor von Nazianz Glauben schenken, der sich mit dem Mithraismus sehr schlecht auskennt? ${ }^{36}$ Robert Turcan zögert nicht, sein Zeugnis für bare Münze zu nehmen und es mit anderen, den Löwen des Mithras gewidmeten Aufzeichnungen in Verbindung zu bringen, so etwa mit diesem Auszug aus Tertullians Contra Marcionem:

Sic et Osiris quod semper sepelitur et in vivido quaeritur et cum gaudio invenitur, recipro carum frugum et vividorum elementorum et recidivi anni fidem argumentantur, sicut aridae et ardentis naturae sacramenta Leones Mithrae philosophantur. ${ }^{37}$

"Das ist auch bei Osiris der Fall: Weil er immer wieder begraben, in allem Lebenden gesucht und mit Freude gefunden wird, führt man [um diesen Mythos zu 
rechtfertigen] den Glauben an die Wiederkehr der Ernten, an den lebendigen Elementen und an den Jahreszyklus als Argument an; in derselben Weise philosophiert man über dieLöwen des Mithras als sacramenta einer trockenen und brennenden Natur.«

Gegen eine breite Mehrheit ${ }^{38}$ möchte R. Turcan aus den leones das Subjekt des philosophantur machen: Die Löwen hätten demnach den Auftrag, die »aridae et ardentis naturae sacramenta" -in denen Turcan "sakramentelle Prüfungen" sieht und insbesondere das »Sakrament des Feuers«, bei dem die milites »das Zeichen mit dem roten Eisen« erhielten ${ }^{39}$ - nicht nur $\mathrm{zu}$ erklären, sondern auch durchzuführen. Sacramenta, das vermutlich $\mu$ votńpı $\alpha$ abbildet ${ }^{40}$, mag sicherlich auf ein Ritual anspielen. Aber handelt es sich tatsächlich um das, was Turcan im Sinn hat? Etwas hellsichtiger erkennt René Braun in dem unpersönlichen Subjekt von philosophantur »die Träger eines Erklärungssystems, die auf philosophische Weise die Löwen des Mithras allegorisieren und in ihnen die Symbole des Feuers sehen ${ }^{41}$ Ein Textabschnitt bei Kaiser Julian vermag uns einen Einblick in derartige Spekulationen zu geben: Attis, der in die Höhle hinab geklettert war, hatte mit der Nymphe angebandelt, der Vertreterin des »feuchten Prinzips der Materie «. ${ }^{42}$ Diese Verbindung, dieser Abstieg

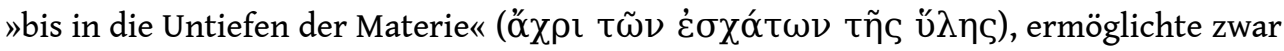
die Genese sämtlicher Dinge, musste aber eines Tages enden, damit Attis sich nicht endgültig darin verlor. Um diesem Ungleichgewicht entgegenzuhalten, schickt HeliosKorybas den Löwen als seinen Helfer; er gilt in der Tat als »entflammt«, »brennend" und als »Ursprung von Hitze und Verbrennung «.43 Julian behauptet also, dass Attis

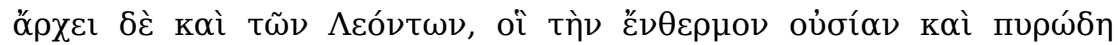

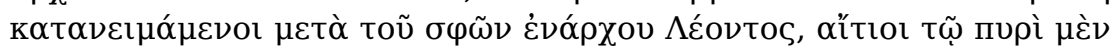

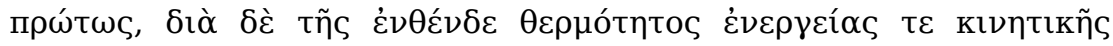

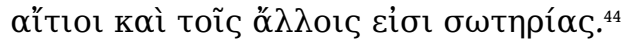

»den Löwen befiehlt, die, da sie sich die wärmende und feurige Substanz in Absprache mit ihrem Anführer, dem Löwen, geteilt hatten, einerseits die Ursachen des Feuers sind und andererseits, dank der von ihm ausgestrahlten Wärme und der kinetischen Energie, ebenfalls die Ursachen für den Erhalt (oder das Heil: $\sigma \omega \tau \eta \rho i ́ \alpha$ ) der anderen [Körper].«

Dank seiner feurigen Eigenschaften wird der Löwe »die Nymphe bekämpfen« und Attis von dem feuchten Prinzip reinigen können.

Im Mithraismus stehen, wie wir noch sehen werden, Löwen in einem engen Zusammenhang mit der Reinigung durch Feuer. Die Rituale, auf die angespielt wurde, waren hingegen völlig harmlos, wie Porphyrios bezeugt:

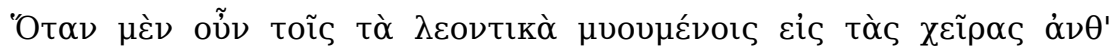

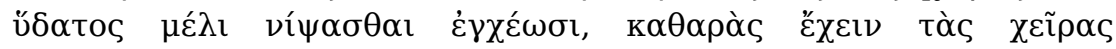

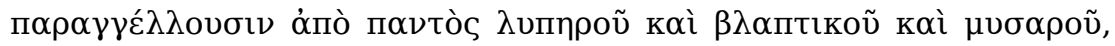

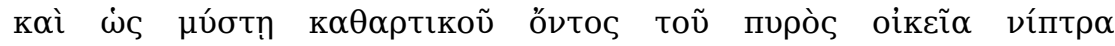

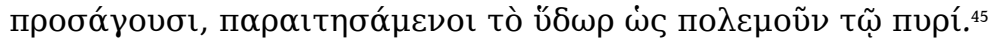

»Und wenn man anstelle des Wassers Honig in die Hände der [in die Mysterien der] leones Eingeweihten gießt, damit sie diese waschen, schärft man ihnen ein, die Hände rein von sämtlichen störenden, schädlichen oder schrecklichen Dingen zu halten; und da das Feuer dazu angetan ist, den Eingeweihten zu reinigen, bringt man (dem Feuer) verwandte, reinigende Flüssigkeiten herbei, während das Wasser als Feind des Feuers verdrängt wird.«

Das als kathartisch angesehene Feuer wird bei dem Ritual nicht als solches benutzt. Seine Rolle übernimmt mit dem Honig eine verwandte Substanz. Häufig wird in Bezug auf diesen Text eine Inschrift in Novae (Steklen in Bulgarien) erwähnt, wo ein zur Weihestufe des Löwen aufgestiegener Myste als melichrisus, «mit Honig Gesalbter « ${ }^{46}$, 
bezeichnet wird. Die Reinigung durch Feuer ist natürlich nichts Neues: "In allen sakralen Riten «, schreibt Servius, "gibt es drei Arten von Reinigung: Entweder reinigt man mit Fackel und Schwefel, wäscht mit Wasser oder aber fächelt mit Luft.« ${ }^{47} \mathrm{Im}$ Mithräum von Dura-Europos verbindet ein fragmentarisches Graffito, unter der Ägide

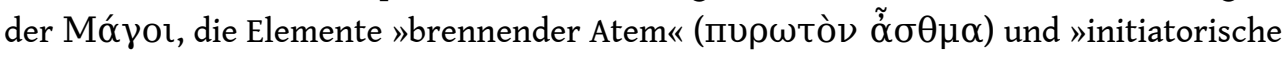
Reinigungsflüssigkeit« ( $\nu[i ́] \Pi \tau \rho o \nu$ ó $\sigma<\sigma>i ́ \omega \nu) .{ }^{48}$ Dieses Graffito, dessen genauer Sinn nicht gesichert ist, bleibt gleichwohl dem Geist der Porphyrios-Beschreibung verhaftet.

Ein letztes, aus dem Mithräum von S. Prisca stammendes Zeugnis spielt seinerseits auf die privilegierten Verbindungen an, die die Löwenmit dem Prinzip des Feuers unterhalten. Die älteste Malereischicht (Ende des 2. Jahrhunderts?), die im Hauptsaal dieses Mithräums (Saal W) freigelegt wurde, hat eine Reihe von Inschriften mit liturgischem Charakter offen gelegt (Nordwand K. 2). ${ }^{49}$ Die Zeilen 16-18 enthalten folgenden Text:

Accipe thuricremos, Pater, accipe, sancte, Leones / per quos thura damus, per quos consumimur ipsi. / Nama Leonibus nouis et multis annis. ${ }^{50}$

»Nimm, Vater, die Weihrauchverbrenner an, nimm, o Heiliger, die Löwen an / durch die wir den Weihrauch darbringen, durch den wir selbst verzehrt werden. / Seid gegrüßt, ihr Löwen, für neue und zahlreiche Jahre.«

Diese Verse stehen neben einem Fresko, das eine Prozession mit männlichen Gestalten darstellt, die durch namentliche Inschriften als Löwen ausgewiesen sind. Die sechs Löwen gehen mit ihren Opfergaben ${ }^{51}$ auf das kleine westlich gelegene Gebäude zu, wo sich eine liegende Statue des Caelus befindet. Zwei analoge Prozessionen, von denen die eine die Löwen umfasste, die andere die sechs ersten mithraischen Weihegrade, liefen an der gegenüberliegenden Wand (I. 2 im Süden) auf den Pater zu. Die in den Inschriften der Wand K. 2 angesprochenen Themen sind in den Wandmalereien streng genommen nicht wiederzufinden. ${ }^{52}$ Die Zeilen 16-17 scheinen jedoch die auf den Pater zulaufende Prozession zu meinen, die sich gewissermaßen mit der auf beiden Seiten des Hauptraumes dargestellten Personenreihe vergleichen lässt. Das eigentliche Wesen dieses Ritus entzieht sich uns. Vermaseren meint in den Sprechern der Zeilen 16-18 die Gläubigen zu erkennen; indem sie sich mit dem von den Löwen verbrannten Weihrauch identifizierten, würden sie auf die Reinigung durch das Feuer anspielen, die auf jeder Stufe der mithraischen Einweihung zum Einsatz komme. Vermaseren denkt hier im Besonderen an die »Feuerprüfung", in deren Verlauf der zukünftige Miles »eine Kauterisierung auf der Stirn " empfing. ${ }^{53}$ Carl-Martin Edsman, der in einer ersten Veröffentlichung ${ }^{54}$ den Verfechtern eines "mit einem glühenden Eisen aufgebrannten Mals« (F.Cumont) Recht zu geben schien, sieht in der Inschrift von S. Prisca unterdessen nur eine "Weihe« durch eine "ganz und gar symbolische« Verbrennung. ${ }^{55}$ Dies ist zweifellos die Interpretation, der es sich anzuschließen gilt.

Unbestritten unterhielten die Löwen des Mithras ein privilegiertes Verhältnis mit dem feurigen Element (s. auch die Attribute des Löwen in Ostia: Blitz, Feuerschaufel, Sistrum ${ }^{56}$ ), und dieses Verhältnis drückte sich in verschiedenen Riten aus, wie etwa in der Ablution mit Honig oder in der Darbringung von Weihrauch. Auch wenn die liturgischen Anweisungen so weit gehen mochten, eine Verbrennung der Gläubigen zu erwähnen (S. Prisca: consumimur ipsi), war diese Formulierung natürlich nicht im wörtlichen Sinne zu verstehen. Die Aufzeichnungen von Tertullian oder Kaiser Julian lenken unsere Aufmerksamkeit $\mathrm{zu}$ stoisch geprägten Hypothesen über das zeugungsmächtige und nährende Feuer, warmen Atem und feuriges Element, das mit 
Gott, der Seele, dem Äther oder sogar mit der Natur in Verbindung gebracht wurde. ${ }^{57}$ Es ist aufschlussreich festzustellen, dass Zeno das nützliche und künstlerische Feuer (пи̃ $\rho$

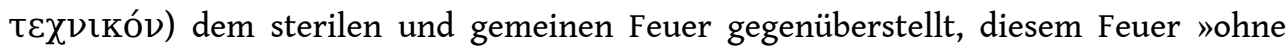
Kunst, das in sich selbst das verändert, von dem es sich ernährt«.$^{58}$ Warum sollte man sich also mit dem gemeinen Feuer kauterisieren lassen, wenn die Mysterien der Löwen ein intelligibles und höheres Feuer versprachen? Es reichte schon, die Symbole von Honig und Weihrauch zu manipulieren. Wenn man den Einfall gehabt hätte, die Mysten mit einem cauterium zu verstümmeln, hätte das Verfahren ohne Frage für einen Skandal gesorgt, und die Empörung wäre zunächst auf Seiten der Heiden, dann der Christen gewesen. Offenkundig haben manche Geister in aufrichtiger oder gespielter Unkenntnis der Tatsachen gerne Mysterienriten dramatisiert, die ursprünglich nichts mit einem körperlichen Einsatz gemein hatten. Diese rhetorische Tendenz, der Gregor von Nazianz gerne nachgibt, sollte von seinen Kommentatoren bis zur Karikatur getrieben werden, und die so entstandenen Beschreibungen trüben sogar noch das Urteil der modernen Historiker. Erinnern wir uns, dass die Eucharistie und Anthropophagie verquickende Verleumdung, die von den Apologeten ${ }^{59}$ angeprangert wurde, auf einen vergleichbaren Mechanismus zurückging.

\section{Zu den »Quellen« des Mithras}

Rekapitulieren wir. Das Feuer ist durchaus imstande, den Mysten zu reinigen

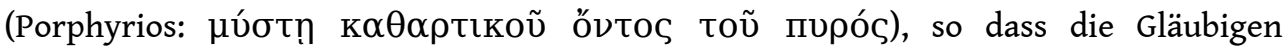
verkünden können: consumimur ipsi (S. Prisca). Die Löwen als »sacramenta einer trockenen und brennenden Natur« (Tertullian) verkörpern dieses für die allgemeine Erzeugung wesentliche feurige Prinzip (Julian, die Stoiker). Die Riten, die jene Thematik inszenieren sollen, bleiben symbolisch und vollkommen harmlos; konkret gab es weder Verbrennungen (Gregor von Nazianz) noch eine Feuerprüfung (Nonnos Mythographus), noch eine Brandmarkung mit dem glühenden Eisen (moderne Geschichtsschreibung).

Es bleibt jedoch die rätselhafte Formel aus dem De praescr. 40, 4: signat in frontibus milites suos. Mithilfe einiger handfester Argumente lässt sich zunächst einmal die Hypothese von einem unauslöschlichen Kennmal ausschalten. Zum einen habe ich bereits erwähnt, dass die signatio der Mithras-Miles sich nicht auf die soldatische Tätowierung beziehen kann, die erst ab Mitte des 4. Jahrhunderts bezeugt ist. Die soldatische Kennzeichnung wurde im Übrigen nicht auf die Stirn geprägt, sondern auf die Hand oder das Handgelenk. Zum anderen wäre es ungeschickt - ein Euphemismus - gewesen, die Mithras-Anhänger der inscriptio frontis, einem Zeichen äußerster Schande ${ }^{60}, \mathrm{zu}$ unterziehen. Hätten die Mithras-Anhänger schließlich ein derart auffälliges Kennzeichen getragen, wäre Tertullian nur einer von vielen Autoren, die davon berichten, und wir wären mit Sicherheit über dessen genaues Wesen im Bilde.

Es bliebe schlussendlich nur eine einzige Lösung übrig, diejenige, die Paul Perdrizet und Franz Joseph Dölger 1911 im Blick hatten: Tertullian hätte von einer punktuellen Kennzeichnung gesprochen, die der christlichen signatio vergleichbar war und möglicherweise in Form einer Salbung mit Chrisam erteilt wurde. Selbst wenn die unwahrscheinliche Hypothese eines »Plagiats« im Sinne von Tertullian ausgeschlossen wäre, bliebe die rituelle Konvergenz darum jedoch nicht weniger verstörend. Nicht, dass es verwunderlich wäre, außerhalb des Christentums auf ein punktuelles 
Bekreuzigungsritual zu stoßen. Vielmehr ist es das Schweigen der anderen antiken Autoren, das hätte überraschen müssen: Sowohl der Mithraismus als auch das Christentum praktizieren eine Bekreuzigung auf der Stirn - ein Sachverhalt, der die Verteidiger wie die Gegner des Christentums gleichermaßen hätte interessieren dürfen. Auch ich hätte mir diese ernüchternde Feststellung zu eigen gemacht, wäre mir nicht eine letzte Lösung plausibel erschienen, um auf zufriedenstellende Weise die meisten der bisher angetroffenen Schwierigkeiten doch noch aus den Weg zu räumen.

\subsection{Für eine Rückverwandlung von frontibus in fontibus (De praescr. $40, \S 4)$}

Ich schlage ganz einfach vor, fontibus an Stelle von frontibus zu setzen $(\S 4$, Z. 6). Hier der Text, gefolgt von meiner Übersetzung:
$\S 2$ (Diaboli) sunt partes interuer interuertendi ueritatem qui ipsas quoque res sacramentorum diuinorum idolorum mysteriis aemulatur. $\$ 3$ Tingit et ipse quosdam utique credentes et fideles suos; expositionem delictorum de lauacro repromittit, $\$ 4$ et, si adhuc memini Mithrae, signat illic in $f[r]$ ontibus milites suos, celebrat et panis oblationem et imaginem resurrectionis inducit et sub gladio redimit coronam. ${ }^{61}$
§ 2 »Die Rolle des Teufels besteht in der Verdrehung der Wahrheit. In den Götzenmysterien rivalisiert er sogar mit dem, was die göttlichen sacramenta recht eigentlich ausmacht. § 3 Er selbst tauft diejenigen, die an ihn glauben, seine Gläubigen; er verheißt die Befreiung der Sünden durch das Bad § 4, und wenn ich mich noch weiter an Mithras entsinne, firmt (der Teufel) bei ihm seine Soldaten in Quellen, feiert er die Darbringung des Brotes, führt er ein Bild der Auferstehung vor und bekränzt er unter dem Schwert «. ${ }^{62}$

Das erste Argument für meine Rückverwandlung beruht auf der Bedeutung von signare, abgeleitet von $\sigma \varphi \rho \alpha \gamma i ́ \zeta \varepsilon \imath \nu$ (besiegeln), das Tertullian häufig benutzt, um die Vorstellungen von Bekräftigung/Firmung, Vervollkommnung und Vollendung auszudrücken, ohne sich auf eine konkrete Kennzeichnung zu beziehen. ${ }^{63}$ Genau mit dieser abstrakten Bedeutung wurden die Wörter $\sigma \varphi \rho \alpha \gamma i ́ \zeta \varepsilon ı \nu /$ signare und $\sigma \varphi \rho \alpha \gamma i ́ \varsigma$ / signaculum in den Paulusbriefen und im Johannes-Evangelium gebraucht. ${ }^{64} \mathrm{Im}$ 2. Jahrhundert verweist diese Terminologie, die künftig auf die Taufhandlung im Allgemeinen angewendet wird, jedoch auf keinen speziellen Signationsritus. Man musste bis zum 3. Jahrhundert warten, bis $\sigma \varphi \rho \alpha \gamma i ́ \zeta \varepsilon \iota \nu$ ausdrücklich das auf die Stirn des frisch Getauften gezeichnete Kreuz meint. ${ }^{65}$ Tertullian erwähnt als erster eine tägliche kreuzförmige signatio als bereits fest verankerte Tradition, für die er den Terminus signaculum verwendet. ${ }^{66}$ In einem auf die Jahre 208-212 zurückreichenden Text spielt der karthagische Gelehrte sogar auf eine signatio an, die nach dem Bad und der Salbung sowie vor dem Auflegen der Hände vollzogen wurde. ${ }^{67}$ Diese signatio nach der Taufe, die durchaus neu zu sein scheint ${ }^{68}$, verdrängt jedoch nicht die traditionelle Bedeutung von signare als Entsprechung zu $\sigma \varphi \rho \alpha \gamma^{\prime} \zeta \varepsilon \iota \nu$, die bei Tertullian am häufigsten auftritt: Nach Art der Griechisch sprechenden Christen überträgt Tertullian die Terminologie des Siegels auf das Taufwasser; da das Bad "Besiegelung des Glaubens" (obsignatio fidei) ist ${ }^{69}$, kann Tertullian vom "Siegel des Bads" (signaculum lauacri) sprechen. ${ }^{70}$ Wie ich versuchen werde zu zeigen, denkt Tertullian an eben jene "Besiegelung " durch die Taufe, wenn er den Teufel des signare in fontibus beschuldigt.

In De praescr. (Kap. 36, §5), einige Seiten vor der für uns relevanten Passage, verwendet Tertullian erneut signare bezüglich der christlichen Initiation in einer für uns äußerst wichtigen Textstelle, in der die Verdienste der Kirche aufgezählt werden: 
[Ecclesia] unum Deum Dominum nouit, creatorem uniuersitatis, et Christum Iesum ex uirgine Marie filium Dei creatoris, et carnis resurrectionem, legem et prophetas cum euangelicis et apostolicis litteris miscet, inde potat fidem; eam aqua signat, sancto spiritu uestit, eucharistia pascit, martyrium exhortatur. ${ }^{71}$

"[Die Kirche] erkennt einen einzigen Gott und Herrn, Schöpfer des Universums, an, Jesus Christus, geboren von der Jungfrau Maria, Sohn des Schöpfergottes; sie erkennt auch die Auferstehung des Fleisches an; sie vermischt das Gesetz und die Propheten mit den Schriften des Evangeliums und der Apostel: Damit stillt sie ihren Glauben; diesen Glauben besiegelt sie mit Wasser (eam aqua signat), bekleidet ihn mit dem Heiligen Geist, nährt ihn mit der Eucharistie, mahnt ihn zum Martyrium«.

Eine kleine Synopse zeigt, wie Kap. 40, §4, nach meiner Rekonstruktion die genaue Parallele zu Kapitel 36, § 5, darstellt:

\begin{tabular}{|l|l|l|l|}
\hline & Christliche Initiation $(36, \S 5)$ & & Mithraische Initiation (40, § 4) \\
\hline & Subjekt: Ecclesia & & Subjekt: Diabolus \\
\hline a) & inde potat fidem; eam aqua signat, sancto spiritu uestit, & a) & signat illic in fontibus milites suos, \\
\hline b) & eucharistia pascit, & b) & celebrat et panis oblationem \\
\hline c) & nouit ... carnis resurrectionem & c) & et imaginem resurrectionis inducit \\
\hline d) & martyrium exhortatur & d) & et sub gladio redimit coronam \\
\hline
\end{tabular}

Diese beiden Passagen stellen eine Parallele her zwischen den christlichen und den mithraischen sacramenta, die Tertullian zufolge vier Gemeinsamkeiten aufweisen: a) die Vervollkommnung oder Besiegelung (signare) durch das Wasser, $b$ ) die Darbietung des Brotes, c) eine Auferstehungslehre, d) die Aufforderung zum Kampf. Bezüglich des letzten Punktes d), der in Kap. 40, §4, in der schwierigen Formel sub gladio redimit coronam angesprochen wird, kann man sich auf die Detailangaben berufen, die Tertullian ein paar Jahre später am Ende von De corona geben sollte. ${ }^{72}$ Unter Punkt $c$ ) ist von einem »Bild der Auferstehung" die Rede. Nach Per Beskow soll Tertullian die Ikonographie des aus einem Felsgestein geborenen Mithras im Sinn gehabt haben, die den Gott meistens mit den Zügen eines Erwachsenen zeigt und insofern zu der Verwechslung zwischen Geburt und Auferstehung Anlass gebe. ${ }^{73}$ Die Haltung des Mithras mit erhobenen Armen (die Schwert, Fackel oder Weltkugel schwenken) mochte an die Haltung der >Drei Jünglinge im Feuerofen` (Daniel) erinnern, die seit Tertullians Epoche ein Sinnbild für die Auferstehung darstellen. ${ }^{74}$ Man kann gleichfalls an die Himmelfahrt des Mithras in der Quadriga des Sol denken, eine Darstellungsform der Apotheose, die auf christlichen Sarkophagen verwendet wurde, um die Entrückung des Propheten Elia, eine andere Präfiguration der Auferstehung, wiederzugeben (2. Kön 2, 11)..$^{75}$

Die oblatio panis unter Punkt $b$ ) findet ihrerseits analoge Elemente in der Ikonographie der von Sol und Mithras gemeinsam eingenommenen Mahlzeit. ${ }^{76}$ Bereits ab der Mitte des 2. Jahrhunderts beschuldigt auch Justinus die »bösen Dämonen", die Eucharistie nachzuahmen, denn in den Mithras-Mysterien »reicht man Brot und eine Wasserschale

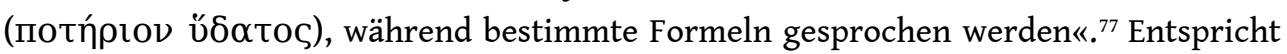
also die signatio aqua/ in fontibus, die Tertullian erwähnt, der bei Justinus 
vorkommenden »Wasserschale«? An anderer Stelle scheut sich der karthagische Gelehrte nicht, signare in Bezug auf ein Initiationsgetränk zu verwenden: »Heutigentags besiegelt (signat) das einem offenen Oberschenkel entnommene Blut, das in der Hand gesammelt und zum Trunk dargeboten wird, die Bellonapriester. ${ }^{78}$ In De baptismo scheint Tertullian den Mithras-Anhängern jedoch ein wirkliches lauacrum zuzuschreiben: »[Die Heiden] werden durch ein Bad in bestimmte Mysterien, wie die von Isis oder Mithras, eingeweiht « ${ }^{79}$, ein Bad, das Tertullian zufolge problemlos in Quellen vor sich gehen könne: „Es besteht nicht der geringste Unterschied, ob jemand im Meer oder in einem Teich gewaschen wird, in einem Fluss oder in einer Quelle (fonte), in einer Zisterne oder einem Becken. ${ }^{80} \mathrm{Im}$ Übrigen liegt hier der Sinn, den die Folge der $\S \S 3$ und 4 nahelegt: »er verheißt die Befreiung von den Sünden durch das Bad (de lauacro) [...] er firmt seine Soldaten in Quellen (in fontibus)«. Vielleicht aber ist in Tertullians Vorstellung auch die Einnahme von Wasser nicht auszuschließen. Sie lässt sich aus dem Verb potare ableiten, das die Parallele a) zwischen De praescr. 36, § 5, und $40, \S 4$ bestimmt: inde potat fidem; eam aquam signat = signat illic in fontibus milites suos. Das Bad und die Einnahme von Wasser schließen sich nicht zwingend aus; es scheint sogar, nach zwei durch Pseudo-Hippolytus überkommenen Aufzeichnungen, als hätten manche Gnostiker die beiden Riten nacheinander praktiziert. ${ }^{81}$

\subsection{Das »Wasserwunder«}

Auch die Ikonographie bietet mögliche Parallelen zu der Formel signat in fontibus milites suos. Eine der auf Mithras-Reliefs häufigsten Szenen zeigt Mithras, wie er mit Pfeil und Bogen auf einen Felsen zielt, um eine Quelle sprudeln zu lassen. ${ }^{82}$ In seinem Korpus verzeichnet Vermaseren mehr als fünfzig Fassungen dieses »Wasser-« oder "Quellwunders $«{ }^{83}$ Mithras wird dabei von ein oder zwei zumeist kniend dargestellten Figuren begleitet, die sich entweder vor der Quelle zum Trinken oder aber vor dem Gott niedergekniet haben, um seinen Beistand zu erbitten (Abb.3-6). Der von Mithras ausgesuchte Felsen scheint bisweilen einer luftigen Wolkenformation zu gleichen. In anderen Beispielen der Mithras-Ikonographie wird das Himmelszelt oft durch Felsen dargestellt. Eubulus führt seinerseits an, dass die speleae ein verkleinertes Bild des von

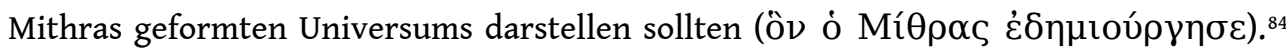
Wie Vermaseren nahelegt, ließ Mithras dem Mythos zufolge aller Wahrscheinlichkeit nach Wasser aus dem Himmelszelt entspringen. ${ }^{85}$ 


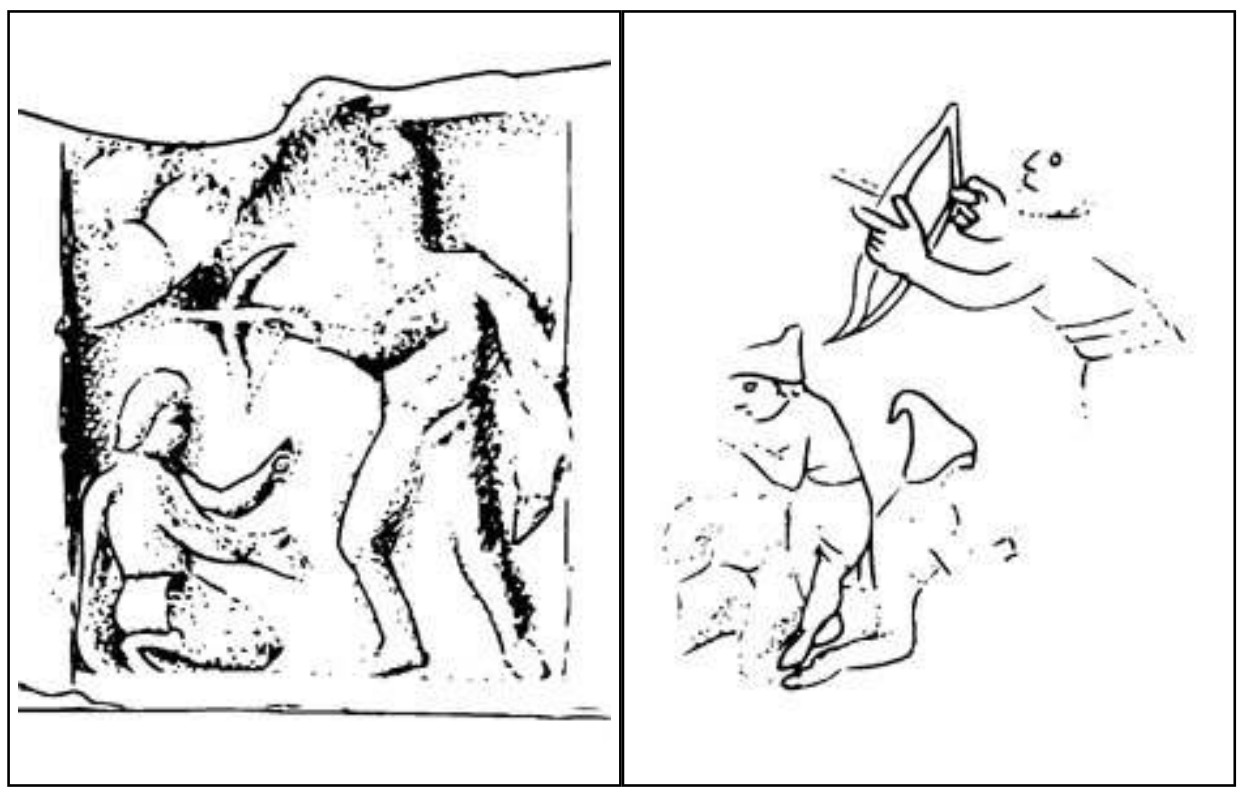

Abb. 3 Mainz, CIMRM 2, Nr. 1225

Abb. 4 Poetovio, CIMRM 2, Nr. 1584

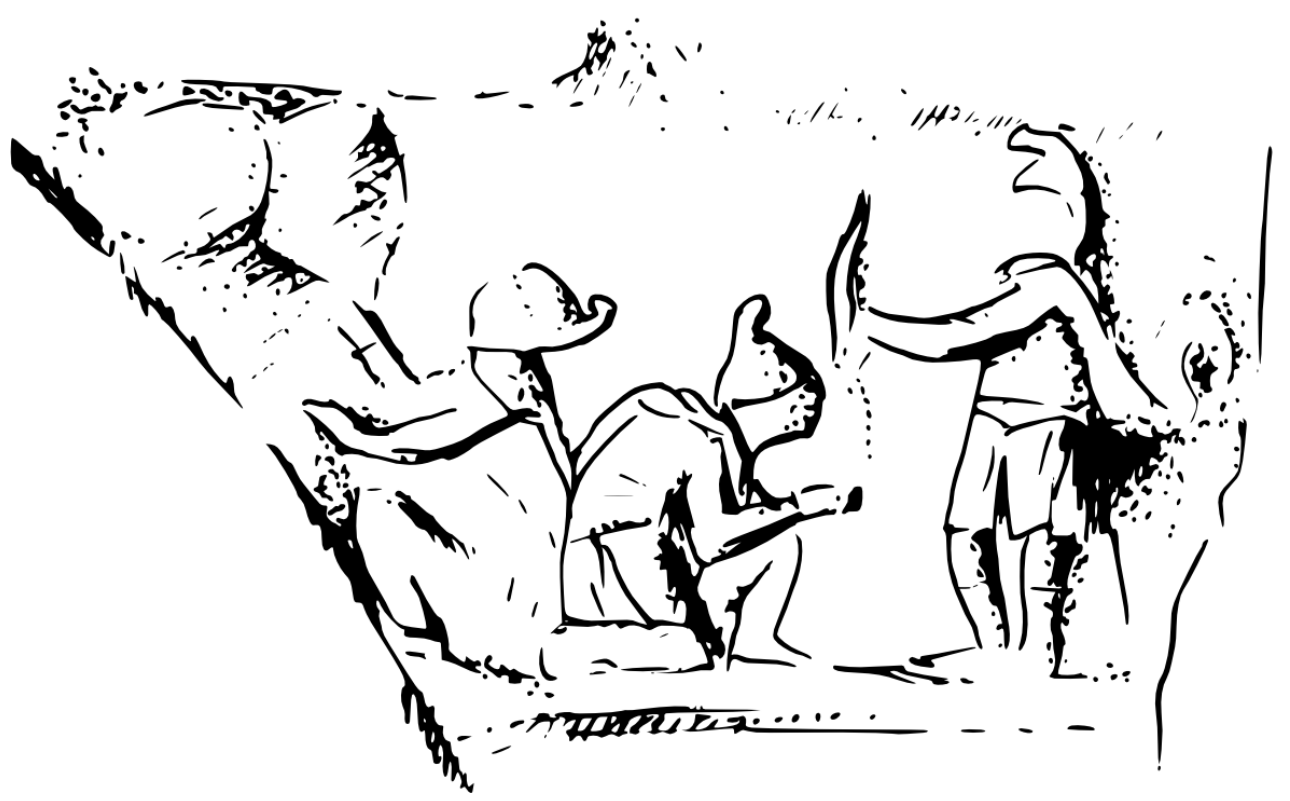

Abb. 5 Osterburken, CIMRM 2, Nr. 1292 


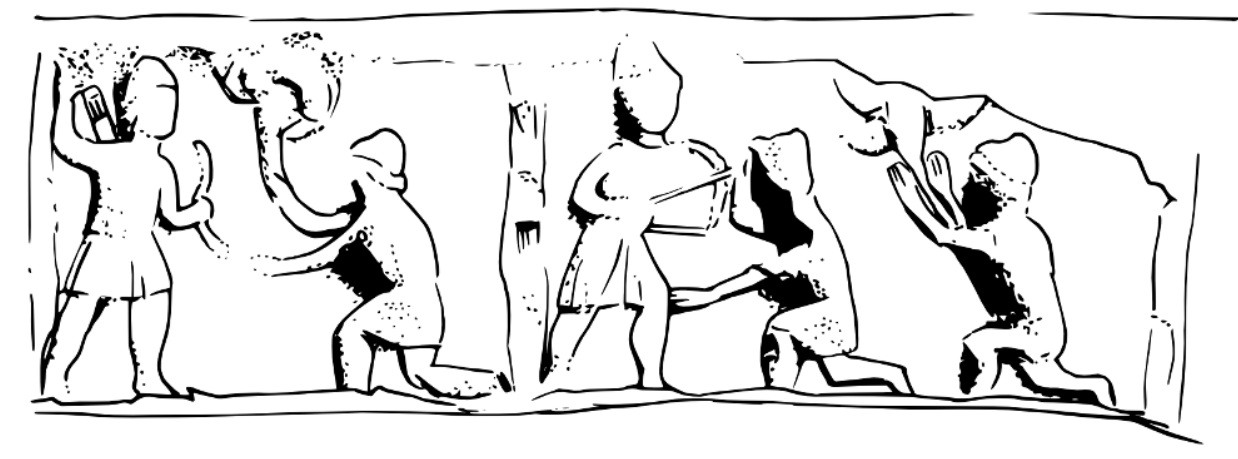

Abb. 6 Besigheim, CIMRM 2, Nr. 1301

In S. Prisca spielt eine Inschriftzeile im Zusammenhang der allgemeinen Fruchtbarkeit der Lebewesen auf das "Wasserwunder « an: "Im Felsen verschlossene Quelle, die du mit deinem Nektar die Zwillingsbrüder gespeist hast « (Fons concluse petris qui geminos aluisti

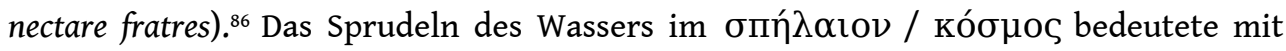
Sicherheit eine grundlegende Etappe in der durch Mithras vorgenommenen Ordnung und Belebung der Welt. Vermaseren schlägt vor, jene durstige »Zwillingsbrüder« als Cautes und Cautopates zu identifizieren ${ }^{87}$ Allerdings hätte in diesem Fall die MithrasIkonographie, die sie fast immer mithilfe eines Attributs unterscheidet (erhobene Fackel für den einen, gesenkte Fackel für den anderen), dasselbe Verfahren zumindest auf eine der zahlreichen erhaltenen »Wunder«-Szenen anwenden müssen. Das persische Gewand der Figuren (phrygische Mütze, kurze, in der Taille geschnürte Tunika, Hose, kurzer Umhang) weist sie lediglich als Landsleute des Mithras aus.

Gab es ein Wasserritual, das dieser Darstellung des "Quellwunders" entsprach? Porphyrios legt dar, dass »man bei Mithras die Quelle durch einen Krater ersetzt « ${ }^{88}$, und eine Statuette aus Dieburg (Abb. 7) scheint ihm recht zu geben: Sie zeigt Mithras, der seinen Bogen auf einen Altar stützt und in der Rechten einen Pfeil hält; zu seinen Füßen ein Gefäß mit Henkeln, das sich als Sinnbild oder Behältnis für das Wunder wirkende Wasser deuten lässt. 


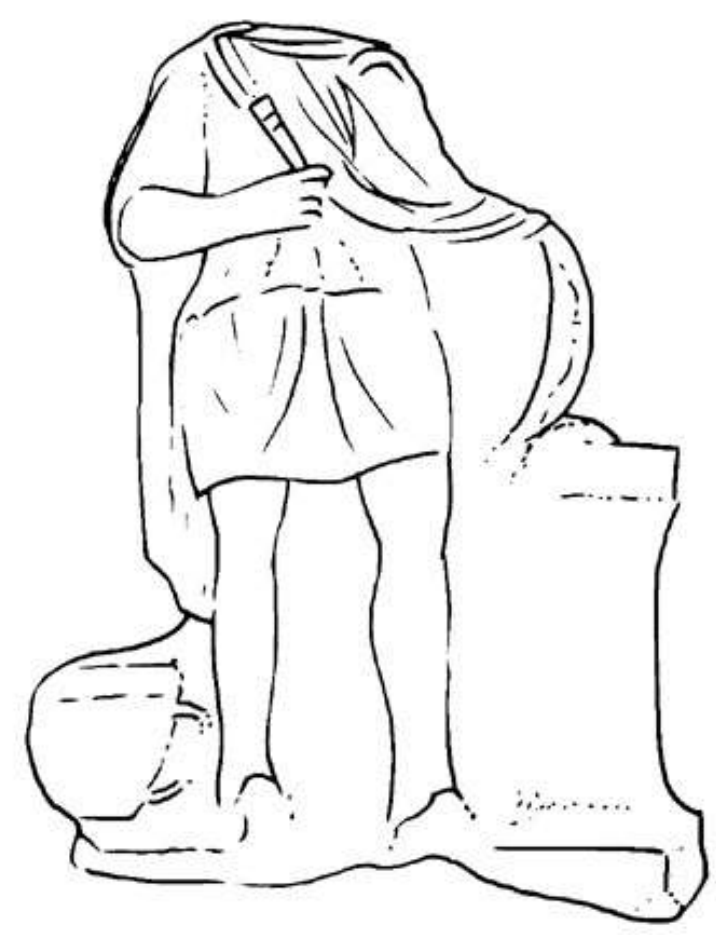

Abb. 7 Dieburg, CIMRM 2, Nr. 1249

Kann man noch weiter gehen? Wie wir gesehen haben, behauptet Tertullian, sowohl im Isis-, als auch im Mithraskult fände die Initiation per lauacrum statt. ${ }^{89}$ Muss man, wie Vermaseren ${ }^{90}$, daraus ableiten, dass die Mithras-Anhänger durch Besprengung getauft wurden? Das hieße, den Apologeten in die Falle zu gehen, die nur allzu schnell bereit sind, den Vergleich (oder aber die Abgrenzung) zwischen Christentum und Heidentum überzustrapazieren. Aller Wahrscheinlichkeit nach ist das lauacrum, das Tertullian in De baptismo den Mithras-Mysterien zuschreibt, seiner Ansicht nach nichts weiter als die signatio in fontibus des De praescr. Der von Tertullian verwendete Plural drückt entweder einen allgemeinen Tatbestand aus (ebenso viele "Quellen« wie speleae) oder einen spezifischen Sachverhalt (mehrere "Quellen« pro spaeleum, wie ein Auszug von Eubulos nahelegt). ${ }^{91}$

Man kann sich die Frage stellen, ob Tertullian diesen Wasserritus nicht aus bildlichen Darstellungen des "Quellwunders" ableitet. Diese Hypothese setzt voraus, dass solche Darstellungen einem Gelehrten aus Karthago schon seit dem späten 2. Jahrhundert zugänglich waren. In Nordafrika finden sich keinerlei Überreste dieser Art, man weiß aber durch Altarwidmungen eines aus Poetovio in Pannonien stammenden Legaten der Legio III Augusta, Marcus Valerius Maximianus, dass der Mithraskult dort seit Anfang der 180er Jahre beheimatet war. Die Ikonographie des "Quellwunders«, in Poetovio Mitte des 2.Jahrhunderts (s. Abb.4) und darüber hinaus an den Rhein- und Donaugrenzen im 2. und 3. Jahrhundert bezeugt, gehörte sehr wahrscheinlich zum Gepäck, das die dem Mithraismus nahe stehenden Offiziere mit nach Afrika nahmen.

Wenn meine Hypothese Anklang findet, dann bezeichnen folglich die milites aus De praescr. die Figuren, die auf der Inschrift in S. Prisca wiederum gemini fratres genannt werden. Tertullian kannte den Weihegrad eines Mithrae miles (De corona, 15, siehe supra), doch nichts lässt die Behauptung zu, dass dieser Grad in einem besonderen Zusammenhang mit dem »Wasserwunder« gestanden hätte. Ihrer ikonographischen 
Darstellung nach konnten die beiden Perser leicht als Soldaten durchgehen. Mit Ausnahme der phrygischen Mütze erinnert ihr Gewand tatsächlich an das der römischen Soldaten im Feldzug (Hose, kurze Tunika mit Ärmeln, Lederriemen, über die Schulter geworfene Chlamys).

\section{Schluss}

31 Wie mir hoffentlich zu zeigen gelungen ist, kann sich die Korrektur von frontibus zu fontibus in De praescr., Kap. 40, §4, auf ein ganzes Bündel übereinstimmender Indizien berufen. Das Wichtigste von allen besteht in der Parallele von vier Termini der Kap. 36, $\S 5$, und 40, §4, (Vervollkommnung durch das Wasser, Darbringung von Brot, Auferstehungslehre, Aufforderung zum Kampf oder zum Martyrium), mit deren Hilfe sich eine Entsprechung zwischen der Vervollkommnung des Glaubens im Taufwasser (eam [fidem] aqua signat) und der Vervollkommnung der an der Quelle Mithras gelabten "Soldaten« herstellen lässt (signat illic in fontibus milites suos). Diese Parallele fügt sich der allgemeinen Absicht Tertullians, die diabolische Nachahmung der christlichen Riten durch die Heiden anzuprangern. Wie zu sehen war, stellt die Ikonographie für Tertullian möglicherweise eine der Informationsquellen dar. Insbesondere die Darstellungen des »Wasserwunders« könnten ihn veranlasst haben, die Begleiter des Mithras als milites zu deuten.

Tertullian hat sich gewiss nicht zufällig für die »Quellen« des Mithras interessiert. Ein ähnliches, Moses zugeschriebenes Wunder (2. Mose 17, 1-7, und 4. Mose 20, 11-12) wurde von den Christen als Präfiguration der Taufe interpretiert. Im Übrigen zeigen ab dem 4. Jahrhundert die bildlichen Darstellungen des Moses-Wunders verwirrende Analogien mit der Ikonographie des Mithras als Wasserspender. Handelt es sich um einen simplen Zufall? Diese Frage, die es sich zu stellen lohnt ${ }^{92}$, steht zu Tertullians Zeiten noch nicht auf der Tagesordnung. Auf Seiten der Texte findet man ab der ersten Hälfte des 3. Jahrhunderts eine Auslegung, die Tertullian sich hätte zu eigen machen können und die der von ihm vorgenommenen Parallele zwischen der christlichen Taufe und der signatio in fontibus der Mithras-Soldaten Auftrieb gegeben hätte: Bei Origines weisen die das Land verlassenden Juden, denen Moses (= Petrus) aus dem Felsen (= Christus) zu trinken gibt, auf die milites Christi voraus, bereit, gegen Amalek (= diabolus) zu kämpfen, nachdem sie sich an der christlichen Lehre gelabt haben (das heißt, nachdem sie getauft wurden) ${ }^{93}$

Das spätere Schicksal von Tertullians Text lässt sich leicht ausmalen. Die in der Formel signat illic in fontibus milites suos enthaltene Anspielung richtete sich an zumindest minimal mit der mithraischen Vorstellungswelt und dem entsprechenden Kult vertraute Leser. Da die signatio frontium schon zu Tertullians Zeiten ein eigenständiger christlicher Ritus war, hielt es der erstbeste von den mithraischen Bräuchen wenig unterrichtete Kopist fatalerweise für angebracht, fontibus als einen Fehler seines Vorgängers für frontibus zu lesen. Dieser Irrtum hat sich vermutlich sehr früh in die handschriftliche Tradition eingeschlichen. Das Aufkommen der soldatischen Kennzeichnung gegen Mitte (oder Ende) des 4.Jahrhunderts konnte in diesem Zusammenhang nur bestärkend wirken. Hatten nicht sogar die neuzeitlichen Historiker geglaubt, bei Tertullian eine Anspielung auf die Tätowierung der Soldaten herauslesen zu können? 


\section{BIBLIOGRAPHIE}

\section{Abkürzungen}

CMG : Corpus medicorum Graecorum, Berlin, $1907 \mathrm{ff}$.

CSEL : Corpus scriptorum ecclesiasticorum latinorum, Wien, $1866 \mathrm{ff}$.

CCSG : Corpus Christianorum, Series Graeca, Turnhout, Brepols.

CCSL : Corpus Christianorum, Series Latinae, Turnhout, Brepols.

CUF : Collection des Universités de France, publiée sour le patronage de l'Association Guillaume Budé, Les Belles Lettres, Paris.

PG : Patrologiae cursus completus, Series graeca, hg. v. Jacques-Paul Migne, 166 Bde., Paris, 18571866.

PL : Patrologiae cursus completus, Series latina, hg. v. Jacques-Paul Migne, 218 Bde., Paris, 18441855.

SC : collection Sources Chrétiennes, Paris, 1943 ff.

\section{Quellen}

Ambrosius: De obitu Valentiniani consolatio, hg. v. O. Faller, CSEL, 73/7, 1955, Sp. 23-184.

Atti e passioni dei martiri, hg. v. A. A. R. Bastiaensen, Mailand, Mondadori, 1987, S. 233-245.

Augustinus: Sermo 317, § 5, PL 38, 1437.

Augustinus: Sermones admixtis quibusdam dubiis, Sermo 8, § 2, PL 46, 839.

Cassius Felix: De la médecine (De medicina), hg. v. Anne Fraisse, CUF, 2002.

Corpus Inscriptionum et Monumentorum Religionis Mithriacae [CIMRM] 1, Nr. 390.

Cosmas Hierosolymitanus: Ad carmina S. Gregorii (über das Gedicht 63 von Gregorios, Carmen VII ad Nemesium, V. 265-266, PG 37, 1573), PG 38, Sp. 506

Gregor von Nazianz: Discours 4-5 (Contre Julien), hg. v. Jean Bernardi, SC 309, 1983.

Gregor von Nazianz: Oratio 39in Sancta Lumina, in: Gregor von Nazianz: Discours 38-41, hg. v.

Claudio Moreschini, SC 358, 1990.

Hieronymus: In Isaiam (Is 44), PL 24, 435D.

Johannes Chrysostomos: In epist. II ad Cor. homil. III, § 7, PG 61, 418A.

Julianus Imperator: Oratio VIII (An die Göttermutter), in: Julien, CEuvres complètes, II, 1, hg. v. Gabriel Rochefort, CUF, 1963.

Justinus: Apologia I, hg. von André Wartelle, Paris, Études augustiniennes, 1987.

Justinus: Dialogus cum Tryphone, hg. v. Philippe Bobichon (Paradosis. Études de littérature et de théologie anciennes, 47/1), Fribourg, Academic Press Fribourg, 2003.

Kyrill von Jerusalem, Katechesen,PG 33. 
Minucius Felix: Octavius, hg. v. Jean Beaujeu, CUF, 1964.

Nonnos Mythographus: In orationem IV Gregorii Nazianzeni commentarius, hg. v. Jennifer Nimmo Smith, CCSG, 27, 1992.

Nonnos Mythographus: In S. Gregorii Orationem in sancta lumina, PG 36, 1072A.

Origenes: In Exodum, Homilia, hg. v. Marcel Borret, SC 321, S. 330-333.

Papiri greci e latini, Florence, 1932, $\mathrm{n}^{\circ} 1162$, S. 102 ff. (Pubblicazioni della società italiana per la ricerca dei papiri greci e latini in Egitto, $\mathrm{X}$ ).

Paulus aus Aigina, Epitomae medicae, hg. v. J. L. Heiberg, CMG, IX 1 und 2, 1921 und 1924.

Plutarch: Isis et Osiris, in: Euvres morales, Bd. 5, 2. Teil, hg. v. Christian Froidefond, CUF, 1988.

Porphyrios: De antro Nympharum, in:ders.: The Cave of the Nymphs in the Odyssey. A Revised Text with Translation by Seminar Classics 609, State University of New York at Buffalo, 1969.

Pseudo-Hippolytus: Refutatio omnium haeresium, hg. v. Miroslav Marcovich, Berlin, 1986

(Patristische Texte und Studien, 25).

Roman Military Records on Papyrus, éd. par R. O. Fink, Cleveland/Ohio, Case Western Reserve University Press, $n^{\circ}$ 83, 1971 (Philological Monographs of the American Philological Association, 36).

Strabo: Geographica, in der Übersetzung und mit Anm. v. A. Forbiger, 2. korr. Aufl., Wiesbaden, Matrixverlag, 2007.

Tertullianus: Adversus Marcionem, III, hg. v. René Braun, SC 399, 1994.

Tertullianus: Apologeticum, hg. v. Jean-Pierre Waltzing, CUF, 1929.

Tertullianus: De anima, hg. v. J. H. Waszink, CCSL 2, 1954.

Tertullianus: De baptismo, hg. von Raymond-François Refoulé, SC 35, 1952.

Tertullianus: De corona, hg. v. Jacques Fontaine, Paris, 1966.

Tertullianus: De paenitentia, hg. v. Charles Munier, SC 316, 1984.

Tertullianus: De praescriptione haereticorum, hg. v. Raymond-François Refoulé, SC 46, 1957.

Tertullianus: De pudicitia, hg. v. Charles Munier, SC 316, 1984.

Tertullianus: De resurrectione mortuorum, hg. v. J. G. Ph. Borleffs, CCSL 2, 1954.

Tertullianus: De spectaculis, hg. v. Marie Turcan, SC 332, 1986.

Tertullianus: Ad uxorem, hg. v. Charles Munier, SC 273, 1980.

Theodor von Mopsuestia, Homilie 2 über die Taufe (Vers 392, auf syrisch erhalten), § 17, aus dem Syrischen übers. von G. Couturier in: L'Initiation chrétienne, gesammelt und herausgegeben von A. Hamman, Paris, 1980, S. 116-117.

Vegetius Renatus, F.: Abriß des Militärwesens: lateinisch und deutsch, mit Einl., Erl. und Indices von Friedhelm L. Müller, Stuttgart, Steiner, 1997.

Vegetius Renatus, F.: Epitoma rei militaris/Das gesamte Kriegswesen, von Fritz Wille neu übersetzt und kommentiert, Aarau / Frankfurt a.M. / Salzburg, Sauerländer, 1986. 


\section{Sekundärliteratur}

Baroin, C. (2002): »Les cicatrices ou la mémoire du corps«, in: Corps romains. Textes réunis par Philippe Moreau, Grenoble, J. Millon, S. 27-46.

Beck, R. (1984): »Mithraism since Franz Cumont«, in: Aufstieg und Niedergang der römischen Welt,II. 17.4., S. 2002-2115.

Beck, R. (2000): »Ritual, myth, doctrine, and initiation in the mysteries of Mithras: New evidence from a cult vessel «, The Journal of Roman Studies, 110, S. 145-180.

Benoît, A. / Munier, C. (1994): Le Baptême dans l'Église ancienne (Ir -III siècles), Bern, P. Lang (Traditio christiana, 9).

Beskow, P. (1979): »Branding in the mysteries of Mithras?«, in: Mysteria Mithrae. Atti del Seminario Internazionale su "La specificità storico-religiosa dei Misteri di Mithra, con particolare riferimento alle fonti documentarie di Roma e Ostia«, Roma e Ostia, 28-31 Marzo 1978, hg. v. Ugo Bianchi, Leiden, Brill, S. 487-501 (EPRO, 80).

Beskow, P. (1994): »Tertullian on Mithras«, in: Studies in Mithraism. Papers associated with the Mithraic Panel organized on the occasion of the XVI ${ }^{\text {th }}$ Congress of the International Association for the History of Religions, Rome, 1990, Rom, L'Erma di Bretschneider, S. 51-60.

Bidez, J. / Cumont, F. (1938): Les mages hellénisés, Bd. 2, Paris, Belles Lettres.

Bousset, W. (1907): Hauptprobleme der Gnosis, Göttingen, Vandenhoeck \& Ruprecht (Forschungen zur Religion und Literatur des Alten und Neuen Testaments, 10).

Braun, R. (1977): Deus Christianorum. Recherches sur le vocabulaire doctrinal de Tertullien, Paris, Études augustiniennes, 2. Aufl.

Braun, R. (1995): Rezension von Robert Turcan, »La >Physica Ratio des >Lions« mithriaques«, Revue des Études Augustiniennes, 41, S. 343 (Chronica Tertullianea et Cyprianea 1975-1994. Bibliographie critique de la première littérature latine chrétienne, Paris, Études augustiniennes, 1999, S. 461).

Clauss, M. (1986): »Mithras und Christus«, Historische Zeitschrift, 243, 265-286.

Clauss, M. (1990): Mythras: Kult und Mysterien, München, Beck.

Clauss, M. (1992): »Miles Mithrae«, Klio, 74, S. 269-274.

Clauss, M. (2000): The Roman Cult of Mithras: The God and his Mysteries, Edinburgh, Edinburgh Univ. Press.

Cumont, F. (1896): Textes et monuments figurés relatifs aux mystères de Mithra, Bd. 2, Brüssel.

Cumont, F. (1933): »Un fragment de rituel d'initiation aux mystères«, Harvard Theological Review, 26, S. $151-160$.

Cumont, F. (1981 [1899]): Die Mysterien des Mithra. Ein Beitrag zur Religionsgeschichte der römischen Kaiserzeit, 5. unveränderte Auflage, Darmstadt, Wissenschaftliche Buchgesellschaft (Nachdruck der v. Kurt Latte besorgten 3. Auflage von 1923).

Demougeot, É. (1961): »PPaganus«, Mithra et Tertullien«, Studia Patristica, 3, S. 354-365.

Dennison, W. (1905): »A new head of the so-called scipio type: an attempt at its identification «, American Journal of Archaeology, 9, S. 11-43.

Dölger, F. J. (1911): Sphragis. Eine altchristliche Taufbezeichnung in ihren Beziehungen zur profanen und religiösen Kultur des Altertums, Paderborn, F. Schönigh. 
Dölger, F. J. (1974 [1929]): »Die Sphragis der Mithrasmysterien«, Antike und Christentum, Bd. I, 2. Aufl., Münster, Aschendorff, S. 88-91.

Dölger, F. J. (1974 [1930]): »Die antiken Köpfe mit dem stehenden und liegenden Kreuz«, Antike und Christentum, Bd. 2, 2. Aufl., Münster, Aschendorff, S. 281-296.

Edsman, C.-M. (1940): Le baptême de feu, Leipzig / Uppsala, Lorentz / Lundequist (Acta seminarii neotestamentici Upsaliensis, 9).

Edsman, C.-M. (1949): Ignis divinus. Le feu comme moyen de rajeunissement et d'immortalité: contes, légendes, mythes et rites, Lund, Gleerup (Publications of the New Society of Letters at Lund, 34).

Gustafson, W. M. (1997): »Inscripta in fronte: Penal tattooing in Late Antiquity«, Classical Antiquity, XVI, S. 79-105.

Heintze, H. von (1957): »Der Feldherr des großen ludovisischen Schlachtsarkophages«, Mitteilungen des Deutschen Archäologischen Instituts Rom, 64, S. 69-91.

Jones, C. P. (1987): »Stigma: tattooing and branding in Graeco-Roman Antiquity«, Journal of Roman Studies, 78, S. 139-155.

Kane, J. P. (1975): »The Mithraic cult meal in its Greek and Roman environment «, in : Mithraic Studies. Proceedings of the First International Congress of Mithraic Studies, Manchester University, 1971, hg. v. J. R. Hinnell, Bd. 2, Manchester, Manchester University Press, S. 313-351.

Lilliebjörn, H. (1933): Über religiöse Signierung in der Antike mit besonderer Berücksichtigung der Kreuzsignierung, Doktorarbeit, Uppsala.

Mohrmann, C. (1954): "Sacramentum dans les plus anciens textes chrétiens«, Harvard Theological Review, 47, S. 141-152.

Nock, A. D. (1927): »Pagan baptisms in Tertullian«, Journal of Theological Studies, 38, S. 289-290.

Perdrizet, P. (1911): »La miraculeuse histoire de Pandare et d'Echédore, suivie de recherches sur la marque dans l'Antiquité«, Archiv für Religionswissenschaft, 14, S. 54-129.

Renaut, L. (2004): Marquage corporel et signation religieuse dans l'Antiquité [mémoire de doctorat], Paris, École Pratique des Hautes Études.

Renaut, L. (2009): »Moïse, Pierre et Mithra, dispensateurs d'eau: figures et contre-figures du baptême dans l'art et la littérature des quatre premiers siècles«, im Internet erhältlich unter: http://hal.archives-ouvertes.fr/hal-00275249/en/.

Rivière, Y. (2004): Le cachot et les fers. Détention et coercition à Rome, Paris, Belin.

Saladino, V. (2004): »[Purificazione] Mondo romano«, Thesaurus Cultus et Rituum Antiquorum, 2, S. 63-87.

Saxer, V. (1988): Les rites de l'initiation chrétienne du II ${ }^{e}$ au VI siècle, Spolète, Tibergraph, S. 188189(Centro italiano di Studi sull'Alto Medioevo, VII).

Trimaille, M. (1996): „Sceau dans le Nouveau Testament «, Supplément au Dictionnaire de la Bible, 12, Paris, Sp. 212-228.

Turcan, R. (1993): »La \Physica Ratio des `Lions« mithriaques (Tert. Marc. 1, 13, 5)«, in: »Foi Raison - Verbe«. Mélanges in honorem Julien Ries, Luxemburg, S. 239-250.

Turcan, R. (2000 [1981]): Mithra et le mithriacisme, Paris, Les Belles Lettres.

Vermaseren, M. J. (1960): Mithra, ce dieu mystérieux, Paris / Brüssel, Sequoia. 
Vermaseren, M. J. / van Essen, C. C. (1965): The Excavations in the Mithraeum of the Church of Santa Prisca in Rome, Leiden, Brill.

Vollgraff, W. (1955): »Une inscription gravée sur un vase cultuel mithriaque«, Koninklijke Nederlandse Akademie van Wetenschappen. Afdeling Letterkunde, Nieuwe Reeks, Deel 18, Nr. ${ }^{\circ} 1-16$, S. 205-218.

Vollgraff, W. (1960): „Le rôle des Lions dans la communauté mithriaque«, in: Hommages à Léon Herrmann, Brüssel (Latomus, 45), S. 777-785.

Vollkommer, R. (1992): »Mithras«, Lexikon Iconographicum Mythologiae Classicae [LIMC], VI, 1, Zürich / München, S. 610-611 (Wasserwunder, Nr. ${ }^{\circ 333-361) .}$

Woods, D. (1999): »The origin of the cult of St. Theagenes of Parium«, Greek Orthodox Theological Review, 44, S. 382-384.

Woods, D. (2003): „St. Maximilian of Tebessa and the Jizya«, in: Hommages à Carl Deroux, hg. v. P. Defosse, Bd. 5: Christianisme et Moyen Âge, Néo-latin et survivance de la latinité, Brüssel (Latomus, 279), S. 266-276.

Zuckerman, C. (1998): „Two reforms of the 370s: Recruiting soldiers and senators in the Divided Empire«, Revue des Études Byzantines, 56, S. 136-139.

\section{NOTES}

1. Die lateinischen und griechischen Zitate wurden nach den eigenen französischen Übersetzungen des Autors ins Deutsche übersetzt. Bei Bedarf wurde auf Tertullians Sämtliche Schriften (Köln 1882) sowie auf Tertullian, Vom prinzipiellen Einspruch gegen die Häretiker (Turnhout 2002) und Tertullian, Von der Taufe / Vom Gebet (Turnhout 2006) zurückgegriffen. [A.d.Ü.]

2. Vgl. Beck (2000), S. 145-180.

3. Tertullian, De corona, Kap. 15, §§ 3-4, hg. v. Fontaine (1966), S. 180-182. Die Logik der Aussage erzwingt nicht unbedingt die Umstellung der Wörter statimque ... dixerit vor atque, wie sie Emil Kroymann in seiner Ausgabe umsetzt (CCSL 2 [1954], S. 1065). In ihren Zusammenhang zurückversetzt, impliziert diese Passage keineswegs, dass die Mithras-Gläubigen eine besondere Stellung in der Armee innehatten (wie es noch von Demougeot [1961], S. 358-359, behauptet wird). Vgl. zu diesem Thema auch Clauss (1992), S. 269-274.

4. Für Jacques Fontaine steht »die Gruppe interposito gladio im absoluten und nicht im instrumentalen Ablativ, wie Franz Cumont meinte«. J. Fontaine, der nicht selbst übersetzt, begnügt sich damit, den symbolischen Wert des Schwerts hervorzuheben, das nach Ansicht von Tertullian auf das Leiden (oder auf den Kampf) »als einer unvermeidlichen Vorbedingung der Verherrlichung « verweise (daher der Hinweis quasi minimum martyrii). Beskow (1994), S. 57, zeigt sich seinerseits in Bezug auf die Formel vorsichtig: "[It] does not necessarily imply that the crown was given at the point of a sword; this ablative absolute may also imply that the sword was held between (the initiate and the crown?) [...]."

5. So zum Beispiel auf dem Mithras-Relief in Osterburken (vgl. dazu Clauss [2000], S. 151).

6. Vegetius, Epitoma rei militaris (Anfang 5. Jahrhundert), I, Kap. 8: Man zeichnet die neuen Rekruten "mit zeichenartigen Punktierungen« aus (punctis signorum) und "mit in die Haut punktierten Pigmenten« (picturis in cute punctis). Vgl. auch Cassius Felix, De medicina (Mitte 5. Jahrhundert), Kap. 13, § I: Die Soldaten tragen Tätowierungen (stigmata) auf der Hand.

7. Atti e passioni dei martiri, hg. v. Bastiaensen (1987), S. 233-245.

8. Vgl. Zuckerman (1998), S. 136-139; Woods (1999), S. 382-384.

9. Woods (2003), S. 266-276. 
10. Ambrosius, De obitu Valentiniani consolatio (im Jahr 392), §§ 58-59, Theodor von Mopsuestia, Katechetische Homelien (um 392, auf Aramäisch erhalten), § 17; Johannes Chrysostomos, In epist. II ad Cor. homil. III, § 7, PG 61, 418A; Hieronymus, In Isaiam (Is 44), PL 24, 435D; Augustinus, Sermo 317, § 5, PL 38, 1437; ders., Sermones admixtis quibusdam dubiis, Sermo 8, § 2, PL 46, 839.

11. Cat. bapt., I, § 3, PG 33, 372C-373A; Cat. bapt., III, § 3, PG 33, 428B; Cat. bapt., XII, § 8, PG 33, 736A; Cat. bapt., XVII, §§ 35-36, PG 33, 1009B-1012A.

12. Cumont (1981 [1899]), S. 144.

13. Vgl. zum Beispiel Bousset (1907), S. 287, Anm. 1.

14. Dölger (1911), S. 43-44. An späterer Stelle (S. 181, Anm. 1) schneidet F. J. Dölger gleichwohl die Tätowierung als mögliche Technik an und spricht von einem »mit der kalten Nadel und mit Farbe punktierten Zeichen«.

15. Perdrizet (1911), S. 117, Anm. 6.

16. Dölger (1974 [1929]), S. 88-91.

17. PSI X 1162 = Papiri greci e latini (»Pubblicazioni della società italiana per la ricerca dei papiri greci e latini in Egitto«, X), Florenz, 1932, Nr. 1162, S. 102 ff.; Cumont (1933), S. 151-160.

18. Zum Beispiel Vermaseren (1960), S. 109.

19. Vollgraff (1955), S. 205-218.

20. Die vollständige Formel wurde von Vollgraff rekonstruiert als: »Te cauterio. I, Saturne, i, Ata[r, i] Opi«. Die in dem Beitrag abgedruckte Kopie und die Fotografie lassen eine solche Transkription allerdings alles andere als naheliegend erscheinen. Starke Bedenken u.a. bei Beck (1984), S. 2029.

21. Vermaseren / van Essen (1965), S.141f. Die Prüfung des Scheintodes soll in einer ausgehobenen Mulde in Saal Z stattgefunden haben. Die Terrakotta weist keinerlei Verbrennungsspuren auf: Mithin war sie also nicht für die Aufbewahrung von Glut gedacht, wie Vollgraff meinte. Vor diesem Hintergrund geht Vermaseren davon aus, dass sie für das Ritual der Brandmarkung dennoch eine Rolle gespielt habe.

22. Von Heintze (1957), S. 69-91. H. von Heintze identifiziert diesen General als Hostilian († 251), den jüngsten Sohn von Kaiser Decius. Diese Hypothesen wurden, zusammen mit denen von Cumont und Vollgraff, von Demougeot (1961), S. 360-364, aufgegriffen.

23. Dölger (1974 [1930]), S. 295 f.

24. Baroin (2002), S. 27-46, insbes. S. 35-42.

25. Ich halte entsprechend nichts von den seinerzeit durch Dennison und Lilliebjörn vorgebrachten Interpretationen, s. Dennison (1905), S. 11-43, und Lilliebjörn (1933), S. 63-66.

26. Paulus Aegineta, Epitomae medicae, VI, Kap. 90, § 4: »Nachdem der Kopf an der verletzten Stelle rasiert wurde, nehmen wir zwei Einkerbungen vor, die sich, dem Buchstaben X vergleichbar, im rechten Winkel durchschneiden. Eine dieser Einkerbungen muss mit der bereits vorher bestehenden übereinstimmen. Anschließend zieht man die Haut nach oben, indem die vier Enden an ihren Spitzen ergriffen werden, um den ganzen zu trepanierenden Knochen

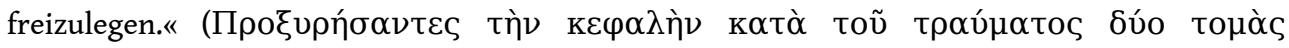

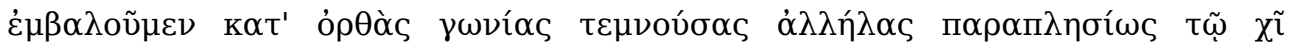

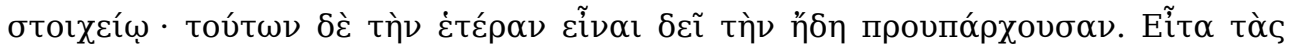

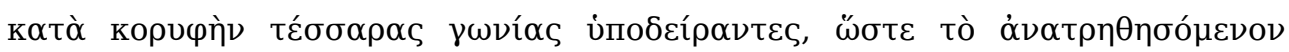

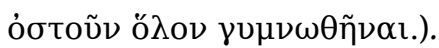

27. Beskow (1979), S. 487-501.

28. In zwei Artikeln wird jedoch der Text Tertullians zitiert. Im ersten übersetzt Manfred Clauss signat illic in frontibus milites suos mit "so bezeichnet er (der Teufel) dort seine Kämpfer auf der Stirne« (Clauss [1986], S. 266). Im zweiten Beispiel ist der Text von De praescr. nicht übersetzt, und unsere Passage bleibt ohne Kommentar (Clauss [1992], S. 270).

29. Turcan (1993), S. 239-250; Turcan (2000), S. 135-138. 


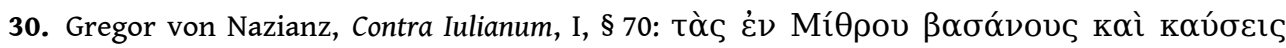

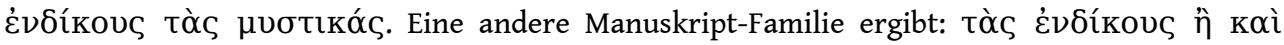

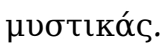

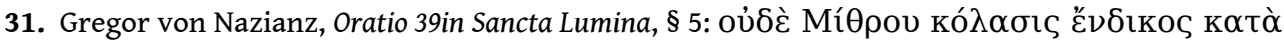

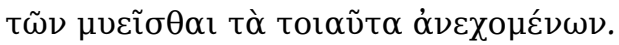

32. Nonnos Mythographus, In orationem IV Gregorii Nazianzeni commentarius, $\S 47$ (a) und $\S 6$ (b), hg. v. Nimmo (1992), S. 115, Z. 5-9, und S. 75, Z. 9-11.

33. Der Kommentar des Nonnos Mythographus wurde von mehreren späteren Autoren aufgegriffen, unter denen Cosmas Hierosolymitanus (8. Jahrhundert) als erster fungiert, $\mathrm{Ad}$ carmina S. Gregorii (über das Gedicht 63 von Gregor, Carmen VII ad Nemesium, V. 256-266, PG 37, 1573), $P G$ 38, Sp. 506 = Cumont (1896), S. 28. Seine aus wörtlichen Zitaten von Nonnos konstruierte Ausführung zu den »Züchtigungen« Mithras gibt uns, übrigens ebenso wenig wie die späteren Exegeten Gregors, keinen Aufschluss (Cumont [1896], S. 29 ff.)

34. Nonnos Mythographus, In S. Gregorii Orationem in sancta lumina, § 9, PG 36, 1072A.

35. Strabo, Geographia, XV, Kap. 3, § 18.

36. Vgl. die überaus seltenen Bezugnahmen des Autors auf den Mithraskult, gesammelt bei Cumont (1896), S. 15.

37. Tertullian, Contra Marcionem, I, Kap. 13, § 5.

38. Vgl. Braun (1995).

39. Turcan (1993), S. 250, und Turcan (2000), S. 137.

40. In den lateinischen Bibelübersetzungen, die von Tertullian und anderen in (Nord-)Afrika

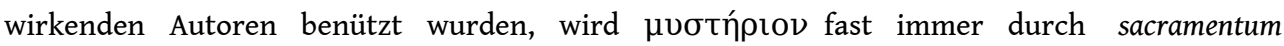
wiedergegeben (vgl. Braun [1977], S. 436 ff.). Bei Tertullian beschränkt sich sacramentum nicht auf den soldatischen Eid; als Entsprechung zu $\mu \nu \sigma \tau$ tńpıov verbindet es gewissermaßen die Bedeutungen von sacrum und arcanum (vgl. Mohrmann [1954], S. 141-152).

41. Braun (1995).

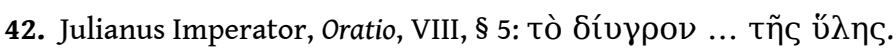

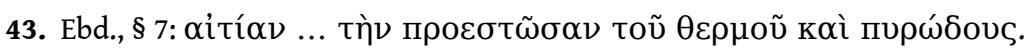

44. Ebd., $§ 8$.

45. Porphyrios, De antro Nympharum, § 15.

46. Turcan (2000), S. 88. In diesem Fall müsste man melichris[t]us lesen.

47. Servius, In Vergilii Aeneidos commentarium, VI, V.740-742: in sacris omnibus tres sunt istae purgationes: nam aut taeda purgant et sulphure, aut aqua abluunt, aut aëre uentilant. Vgl. Saladino (2004), S. 76.

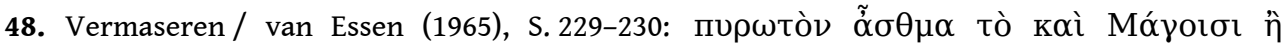
$\nu[i ́] \Pi \tau \rho о \nu$ ó $<\sigma>i ́ \omega \nu . ~ V g l . ~ B i d e z /$ Cumont (1938), S. 155.

49. Vermaseren / van Essen (1965), S. 187 ff.

50. Originaltext der ersten beiden Verse: accipe thuricremos pater accipe sancte leones / pir quos taura damus, pir quos consumimur ipsi. Vollgraff (1960), S. 777-785, geht von einer semantischen Entsprechung zwischen consumimur (consumere: verbrauchen, verbrennen) und consummamur (consummare: vollenden, vervollständigen) aus. Diese Lesart vermochte zwar nicht zu überzeugen (vgl. Beck [1984], S. 2029), wurde aber dennoch von Turcan ([1993], S. 249, und [2000], S. 138) wieder aufgegriffen.

51. Diese sind schwer $\mathrm{zu}$ bestimmen: Wildschwein, kleiner gelber und unbestimmt pyramidenförmiger Gegenstand (Kuchen oder Brot?), Gefäße u.a.

52. Zitieren wir einige erhaltene Wörter, zum Beispiel Z. 1: „Fruchtbare Erde du, aus der Pales alles schafft " (Fecunda tellus cuncta qua generat Pales); Z. 4: »Im Felsen verborgene Quelle du, die die Zwillingsbrüder gespeist hat « (Fons concluse petris qui geminos aluisti nectare fratres); Z. 14: »Und du hast uns gerettet durch die Hingabe eines ewigen Blutes « (Et nos servasti eternali sanguine fuso).

53. Vermaseren / van Essen (1965), S. 228-229. 
54. Edsman (1940), S. 138, Ende von Anm. 1.

55. Edsman (1949). Der Autor widmet den Mithras-Mysterien einige Seiten (S. 219-224). Manche wichtige Quellen werden zitiert (Nonnos Mythographus, Porphyrios). In seiner Lesart der Inschrift von S. Prisca wird der Autor durch die früheren Auslegungen irregeführt (hujus ramos statt thuricremos). In seiner Darlegung äußert sich C.-M. Edsman kein einziges Mal deutlich zum Vorkommen beziehungsweise Fehlen einer Kauterisierung im Mithraismus.

56. Das Sistrum ist das Attribut der mit $\Sigma \tilde{\omega} \theta$ ıৎ gleichgesetzten Isis. Plutarch erklärt in Isis und Osiris, § 21, dass »Isis' Seele von den Griechen Hund und von den Ägyptern Sôthis genannt wird«.

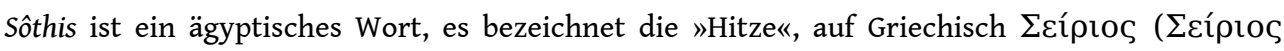

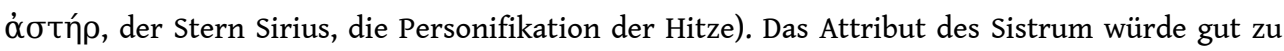
den »sacramenta einer trockenen und brennenden Natur « passen, von denen Tertullian spricht.

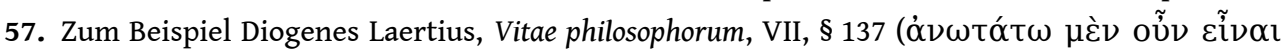

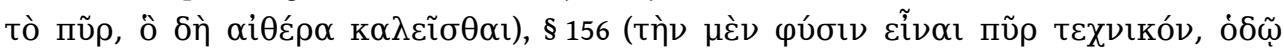

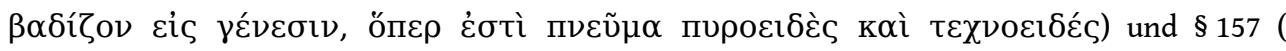

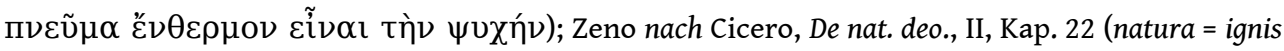
artificiosus); Zeno nach Cicero, Tusculanes, I, Kap. 9 (animus = ignis; Strobaeus, Anth. I, Kap. 49, § 1 b (

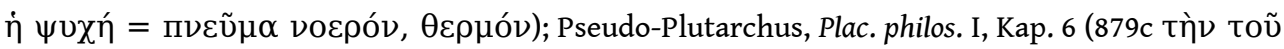

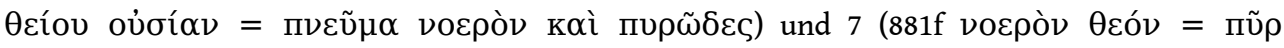

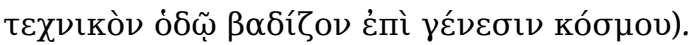

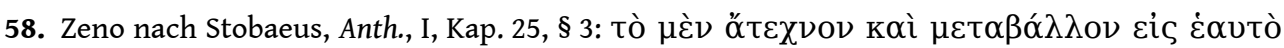

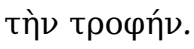

59. Tertullian, Apologeticum, Kap. 7, § I; Minucius Felix, Octavius, Kap. 9, § 5, Kap. 30, § I.

60. Vgl. Jones (1987), S. 139-155, und, für die römische Epoche, Rivière (2004), S. 279-292, besser als die Arbeit von Gustafson (1997), S. 79-105.

61. Tertullianus, De praescriptione haereticorum, Kap. 40, §§ 1-4, hg. v. Refoulé (1957), S. 144-145. Die sechs Manuskripte, die De praescr. überliefern, weichen nicht nennenswert voneinander ab.

62. Die Wendung redimit coronam ist problematisch. Man kann redimit von redimere (zurückkaufen) ableiten oder aber von redimire (bekränzen). Das erste Verb ist auf den Sinn bezogen unbefriedigend, während das zweite eher nach einem objekt im Ablativ verlangen würde. Auch die Bedeutung von sub gladio ist in Anbetracht der Parallelstelle in De corona ungeklärt (vgl. weiter oben, Anm. 3).

63. Vgl. ebenfalls Roman Military Records on Papyrus, N. 83 = P. Doura 97. Auf diesem militärischen Papyrus aus Dura Europos (251 nach Chr.) sind die Ankäufe von Pferden verzeichnet, die im Laufe der sechs vergangenen Jahre für die Cohors XX Palmyrenorum getätigt wurden. Ein mit einer Zuchtmarke ausgestattetes Pferd kann als notatus bezeichnet werden. Hingegen bedeutet signatus $a b N N$ entsprechend zu den Wendungen probatus ab und aestimatus $a b$, dass das Pferd von einem beliebigen Beamten für den Gebrauch durch einen beliebigen Reiter beglaubigt wurde. Diese Beglaubigung, die auf dem Papier stattfindet, beinhaltet keine Kennzeichnung des Tieres.

64. Trimaille (1996), Sp. 212-228.

65. Renaut (2004), S. 772-779.

66. De corona, Kap. 3, § 4: "Gleich welcher Beschäftigung wir nachgehen, wir reiben (terimus) unsere Stirn mit dem signaculum«; Adv. Marc., III, Kap. 22, §§ 6-7: »signaculum frontium«; Ad uxor., II, Kap. 5, § 3: »wenn du dein Bett und deinen Körper bezeichnest (signas)«.

67. De resur. (Phase unter montanistischem Einfluss), Kap. 8, §3: „Caro abluitur, ut anima emaculetur; caro unguitur, ut anima consecretur; caro signatur, ut anima muniatur; caro manus inpositione adumbratur, ut anima spiritu inluminetur«. Dabei handelt es sich um die einzige ausdrückliche Erwähnung einer nach der Taufe vorgenommenen signatio bei Tertullian.

68. Origines, der seinerseits ebenfalls mit der täglichen kreuzförmigen signatio auf der Stirn vertraut ist, bezeugt die Existenz einer vom Bad getrennten Salbung im Orient ab dem ersten Drittel des 3. Jahrhunderts. Allerdings weist nichts darauf hin, dass diese postbaptismale Salbung 


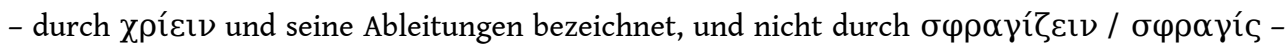
auf der Stirn und in Kreuzform erteilt wurde. Siehe Saxer (1988), S. 188-189. Zu den postbaptismalen Riten, siehe Benoît / Munier (1994), S. XXXIV-XXXV.

69. Tertullian, De paenitentia, Kap. 6, § 14 .

70. Tertullian, De pudicitia, Kap. 9, § II. Der Ursprung dieser Bedeutung bleibt unklar. In meiner Dissertation (Renaut [2004], S. 726-762) habe ich vorgeschlagen, sie auf Seiten des heterodoxen jüdischen Baptismus des 1. und 2. Jahrhunderts zu suchen, deren Terminologie u.a. in manchen Texten von Nag Hammadi überlebt haben könnte.

71. Tertullian, De praescriptione haereticorum, Kap. 36, § 5 .

72. Vg. ebd.

73. Beskow (1994), S. 59.

74. S. zum Beispiel Tertullian, De resur., Kap. 58, §§ 6-10. Justinus, Dialogus cum Tryphone, Kap. 70,

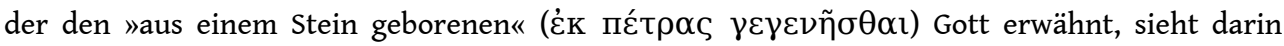
lediglich eine Nachahmung der Präfigurationen Christi als Petrus/Stein (Dn 2, 34, Is 33, 13-19). Firmicus Maternus polemisiert zu demselben Thema, ohne die Auferstehung anzusprechen (De errore profanarum religionum, Kap. 20, §§ 1-6).

75. Es ist interessant, dass Tertullian in De spectaculis, Kap. 23, § 2, im Lenker des Zirkuswagens eine diabolische Nachahmung der Himmelfahrt des Propheten Elia sieht; er geht allerdings davon aus, dass letzterer, der von der Erde entrückt wurde, ohne zu sterben, nicht im eigentlichen Sinne auferstanden ist (De anima, Kap. 35, § 6).

76. Vgl. z.B. das Fresko in S. Prisca (Vermaseren / van Essen (1965), S. 152-153, und Abb. LVIILVIII). Das Bankett von Sol und Mithras ist häufig als Nebenszene auf Mithras-Reliefs dargestellt.

77. Justinus, Apologia I, Kap. 66, §4. Das Mithras-Mahl umfasste selbstverständlich weitere Nahrungsmittel (Fleisch der geopferten Tiere, Wein etc.). Siehe Kane (1975).

78. Tertullian, Apologeticum, Kap. 9, § 10.

79. Tertullian, De baptismo, Kap. 5 , § I: Nam et sacris quibusdam par lauacrum initiantur [nationes], Isidis alicuius aut Mithrae. Siehe Nock (1927), S. 289-290.

80. Ebd., Kap. 4, §3; S. 70. Diese Bemerkung trifft auf die unterschiedlichen Formen der christlichen Taufe zu, auf die von Johannes im Jordan (Matth 3, 6), von Petrus im Tiber und von Philippus mit einem zufällig am Wege gefundenen Wasser vollzogene Taufe (Apostel 8, 36).

81. Pseudo-Hippolytus, Refutatio omnium haeresium, V, Kap. 19, § 21 (eine den Sethianern zugeschriebene Rede): Das Wort hat sich, "nachdem es in die schamvollen Geheimnisse (

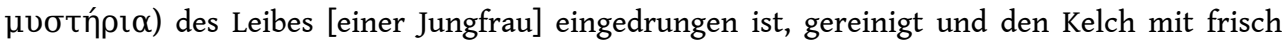

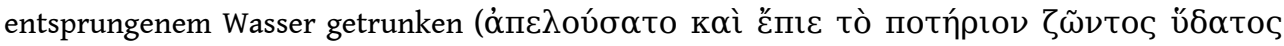

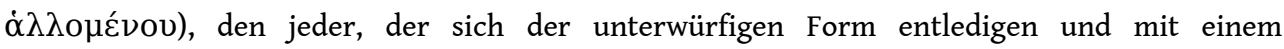
himmlischen Gewand kleiden möchte, unbedingt trinken (пєєі̃)) muss«; V, Kap. 27, § 2 (die Geheimnisse des Gnostikers Justinus): »Wenn er diesen Eid abgelegt hat, wird der Eingeweihte in

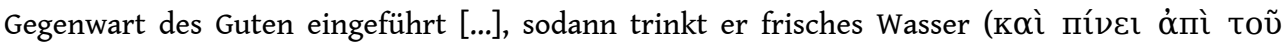

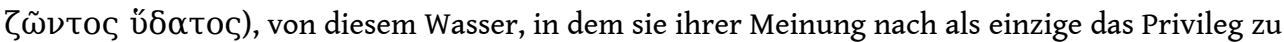

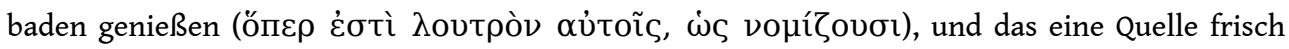
entsprungenen Wassers ist."

82. Siehe Vermaseren (1960), S. 71-74.

83. In Rom kennt man nur eine solche Szene (Fresko des Mithräum im Palazzo Barberini, CIMRM 1, Nr. 390). Die meisten Beispiele stammen aus der Rheingegend (CIMRM 2, 1960, index, S. 411, s. v. watermiracle). S. die jüngste Bestandsaufnahme von Rainer Vollkommer (1992), S. 610-611 (Wasserwunder, Nr. 333-361). Im Mithräum von Dura-Europos (3. Jahrhundert nach Chr.) sieht man in einer der Szenen der Kultnische Mithras allein, stehend, mit gespanntem Bogen, allerdings ohne Wiedergabe des Felsens (Vollkommer [1992], S.356, Nr.300). Die beiden Darstellungen in Rom und Dura sind die einzigen Spuren einer Ikonographie des »Wasserwunders« außerhalb der Rhein- und Donaugebiete. 
84. Eubulos (spätes 1. Jahrhundert n. Chr.) nach Porphyrios, De antros Nympharum, § 6.

85. Vermaseren (1960), S. 73.

86. S. Prisca, Wand K. 2, untere Schicht (um 195), Z. 4, Vermaseren / van Essen (1965), S. 187, und Kommentar, S. 193-200. Die erste Zeile ergibt: „Fruchtbare Erde, aus der Pales alles erschafft« (Fecunda tellus cuncta qua generat Pales), und die dritte »Unde omn...laetas... a (?) ... amant sua».

87. Vermaseren / van Essen (1965), S. 193-194 (die gegenüber den beiden Dioskuren Castor und Pollux bevorzugte Hypothese).

88. Porphyrios, De antro Nympharum, § 17: In der Grotte der Nymphen (Odyssee, XIII, 105) »sind Krater die Symbole der Quellen, so wie bei Mithras die Quelle durch einen Krater ersetzt wird« (

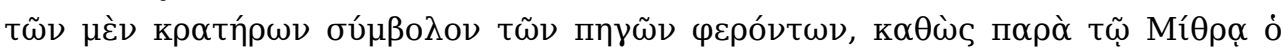

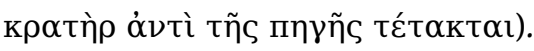

89. De bapt., Kap. 5, § 1, (vgl. weiter oben, Anm. 78).

90. Vermaseren / van Essen (1965), S. 141. Der Saal Y des Mithräumsvon S. Prisca, wichtigster Anbau/Nebenraum des spelaeum (Saal W), weist an seiner Nordwand eine Arkadenöffnung auf, vor der sich ein rechteckiges Podest erhebt. Dort eingelassen fand man ein Becken aus grobem Ton mit einem Durchmesser von $71 \mathrm{~cm}$, was den Anlass zu Vermaserens Vermutung gab: Der am Podest angelangte Myste habe sich niedergekniet und seinen Kopf über das mit Wasser gefüllte Becken gehalten, während die Hände auf den Seiten abgestützt worden seien. Ein (Pater oder Heliodromus) habe ihm mit einer patera Wasser über den Kopf gegossen. Als archäologische Parallelen erwähnt Vermaseren weitere, auf den seitlichen Bänken in den Mithräen von Carnuntum, Heddernheim und Königshofen gefundene Becken. Diese Gefäße könnten gleichwohl zu ganz anderen Zwecken genutzt worden sein.

91. Eubulos nach Porphyrios, De antro Nympharum, § 6: »Zoroaster hatte Mithras, Schöpfer und

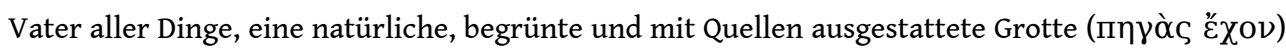
geweiht."

92. Ich habe im Rahmen des von Ivan Foletti und Serena Romano an der Universität von Lausanne organisierten Studientages Baptême et baptistères eine Antwort zu geben versucht. Die Kolloquiumsakten erscheinen voraussichtlich 2009 im Verlag Viella (Rom). S. auch den OnlineVorabdruck meines Beitrages»Moïse, Pierre et Mithra, dispensateurs d'eau: figures et contrefigures du baptême dans l'art et la littérature des quatre premiers siècles«.

93. Origenes, In Exodum, § 3, SC 321, S. 330-333.

\section{INDEX}

Schlüsselwörter : Mithraskult, Mithraismus, Kauterisierung, signatio

Mots-clés : culte de Mithra, mithriacisme, cautérisation, signatio

\section{AUTEURS}

\section{LUC RENAUT}

Luc Renaut promovierte an der École pratique des hautes études (Paris) und ist assoziiertes Mitglied des Laboratoire HeRMA (Poitiers). Nähere Informationen finden Sie hier. 